Utah State University

DigitalCommons@USU

$5-2012$

\title{
Young Children's Mathematics References During Free Play in Family Child Care Settings
}

Shawnee M. Hendershot

Utah State University

Follow this and additional works at: https://digitalcommons.usu.edu/etd

Part of the Communication Commons

\section{Recommended Citation}

Hendershot, Shawnee M., "Young Children's Mathematics References During Free Play in Family Child Care Settings" (2012). All Graduate Theses and Dissertations. 1113.

https://digitalcommons.usu.edu/etd/1113

This Thesis is brought to you for free and open access by the Graduate Studies at DigitalCommons@USU. It has been accepted for inclusion in All Graduate Theses and Dissertations by an authorized administrator of DigitalCommons@USU. For more information, please contact digitalcommons@usu.edu.

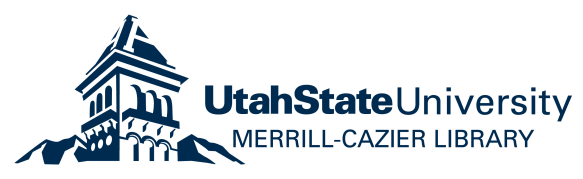




\title{
YOUNG CHILDREN'S MATHEMATICS REFERENCES DURING \\ FREE PLAY IN FAMILY CHILD CARE SETTINGS
}

\author{
by
}

Shawnee M. Hendershot
A thesis submitted in partial fulfillment of the requirements for the degree
of
MASTER OF SCIENCE
in

Family, Consumer, and Human Development

Approved:

Dr. Ann M. Berghout Austin

Dr. Shelley L. Knudsen Lindauer

Major Professor

Committee Member

Dr. Troy E. Beckert

Dr. Mark R. McLellan

Committee Member

Vice President for Research and

Dean of the School of Graduate Studies

\section{UTAH STATE UNIVERSITY \\ Logan, Utah}

2011

Copyright (C) Shawnee Hendershot 2011

All Rights Reserved 


\author{
ABSTRACT \\ Young Children's Mathematics References During \\ Free Play in Family Child Care Settings \\ by \\ Shawnee Hendershot, Master of Science \\ Utah State University, 2011
}

Major Professor: Dr. Ann M. B. Austin

Department: Family, Consumer, and Human Development

This study examined the mathematics talk that children engage in during free play in their non-parental, family child care environments. Audio tapes of children during free play were transcribed and coded for different types of mathematical references using a coding scheme. Types of math talk included: (a) classification, (b) magnitude, (c) enumeration, (d) patterns and shapes, (e) spatial reasons, and (f) part/whole. Results showed that children used spatial relations more than other types of mathematical references. Children's math talk was compared based on their gender and age. Results showed that, on average, children who were older than 40 months referenced mathematics more often than younger children. Also, males were more likely to reference math during free play than were females. Children's math talk was also analyzed in comparison to provider education and experience. It showed that when 
providers had CDA or 2-year degrees, children under their care referenced math more frequently. 


\title{
PUBLIC ABSTRACT
}

\author{
Young Children's Mathematics References During \\ Free Play in Family Child Care Settings
}

by

Shawnee Hendershot, Master of Science

This study was undertaken to determine how children use math in their everyday activities, which includes caregiving environments outside of their home. Audio recordings were taken of children while they played. The researcher typed transcripts of the audio recordings in order to search for references to math. The different types of math that the children used were: (a) classification, (b) magnitude, (c) enumeration, (d) patterns and shapes, (e) spatial reasons, and (f) part/whole. An example of classification would be a child sorting blocks into groups based on shape. Magnitude is used when a child uses phrases to compare two or more items like "a lot" or "more higher." Enumeration is when a child uses actual number words like "three." Pattern and shape concepts include a child building a tower out of blocks and proclaiming the tower to be in the shape of a square. This could also include a child stating a pattern of blocks being "red, black, red, black," and so forth. Examples of spatial relations would include references to "over, under, on, around," and so forth. Finally, the part/whole concept is when a child references something as being part or whole like a "whole pizza." 
Results showed that children frequently used math in their playtime activities. Boys were more likely than girls to reference math. Also, children who were older than 40 months, or just over 3 years old, used math more often when they played. One result also suggested that when providers have specific training in how to care for children, for example a child development associate credential (CDA), children in their care referenced math more.

Overall, the results of the study indicate that math is often used by children when they play. It also shows that children use various types of math when playing. It would be helpful to further train caregivers so they could know how to continue to foster children's use of math in playing as well as in other areas. 


\section{DEDICATION}

I would give thanks to my mom who was dedicated in teaching me a love for learning. Without her support, I would never have gotten this far in my education. She has given me such needed support throughout this research process. I will forever be grateful for her asking on a regular basis, “Are you done yet?” Yes, Mom, I am finally done. 


\section{ACKNOWLEDGMENTS}

I would like to thank Dr. Ann Austin for giving me the opportunity to work with her and her data. I strongly appreciated her help and support during this research project. She was fundamental in giving encouragement and advice. Her background and training in this area were extremely helpful. Thank you so much, Ann. She also introduced me to a key player in the research, Dr. Belinda Blevins-Knabe. Belinda's insights and expertise were crucial to this project. Her help in coding was particularly useful. I couldn't have

done with without you, Belinda. I look forward to my continued association with both of these wonderful scholars.

Shawnee Hendershot 


\section{CONTENTS}

\section{Page}

ABSTRACT. iii

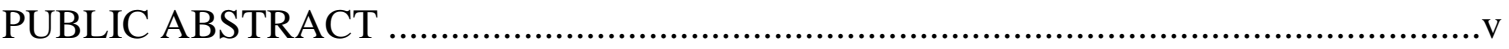

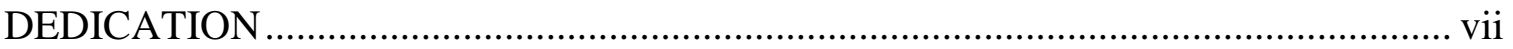

ACKNOWLEDGMENTS ................................................................................ vii

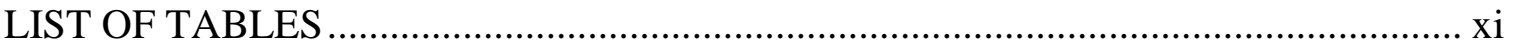

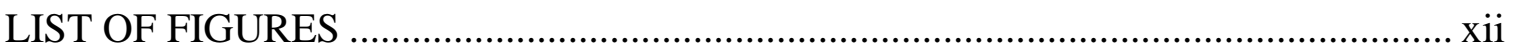

\section{CHAPTER}

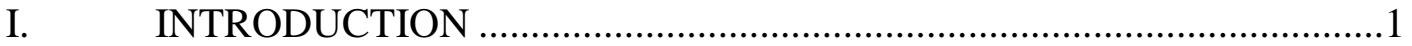

Theoretical Framework ...............................................................2

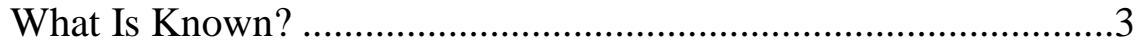

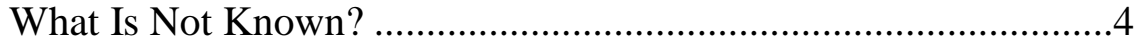

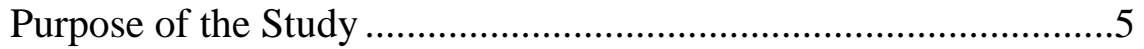

Research Questions .............................................................5

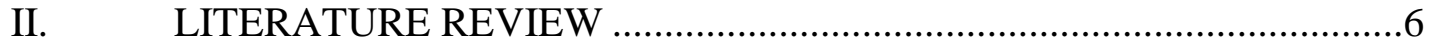

Why the Need for Mathematics Skills? .......................................6

Mathematics Instruction in Pre-kindergarten..................................8

Play Activities and Math........................................................11

Early Mathematics Concepts ...................................................12

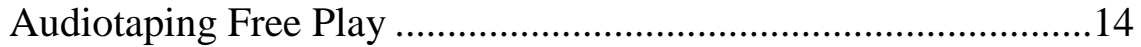

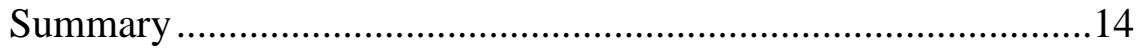

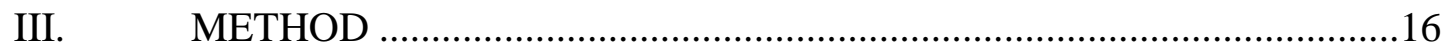

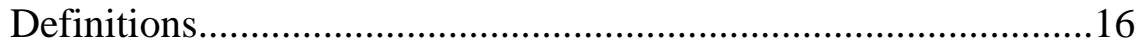

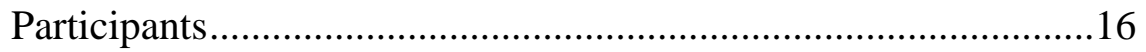

Data Collection .................................................................... 18

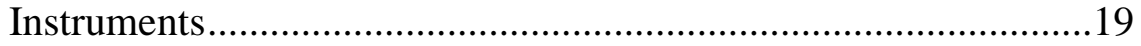

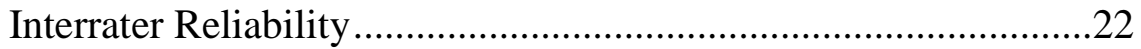

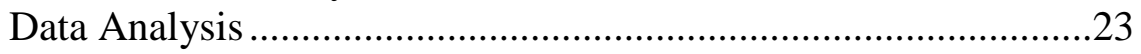




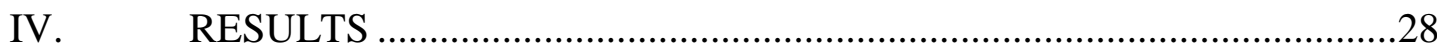

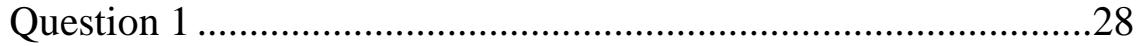

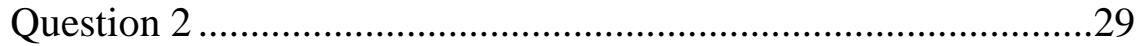

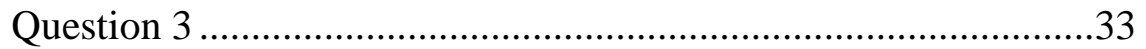

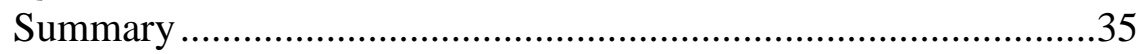

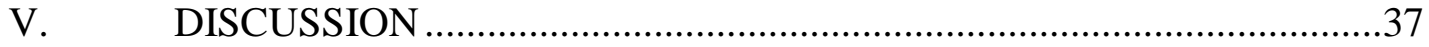

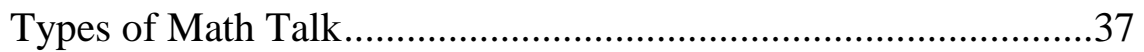

Provider Education and Experience...........................................39

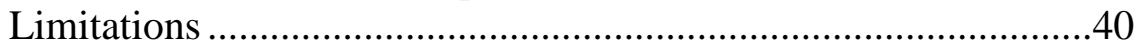

Future Research .................................................................41

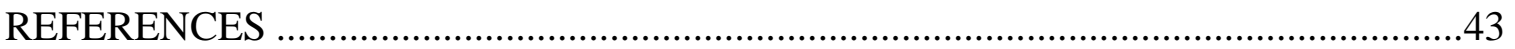

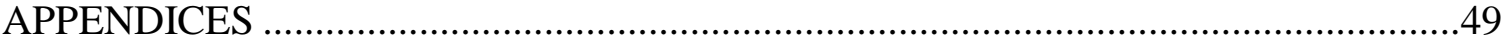

Appendix A. Coding System for Mathematical Content Step 1........................50

Appendix B. Coding System for Mathematical Content Step 2........................52

Appendix C. Code Book for Step 2 ...........................................................56

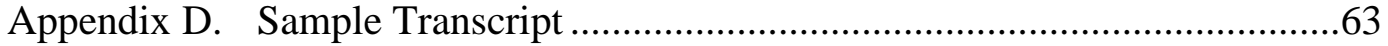

Appendix E. Sample Coded Transcript.........................................................65 


\section{LIST OF TABLES}

Table $\quad$ Page

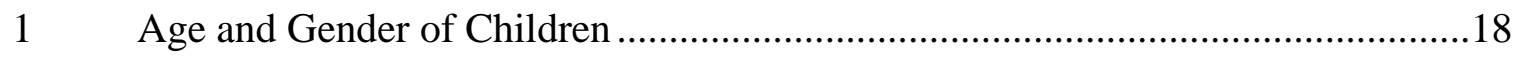

2 Children Divided by Age and Gender According to the

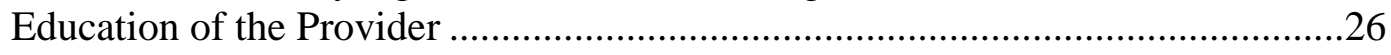

3 Children Divided by Age and Gender According to the

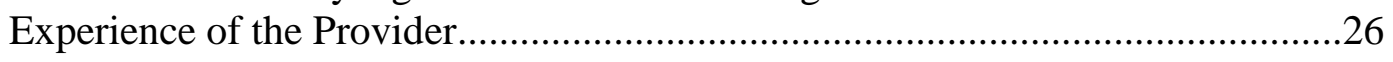

$4 \quad$ Number of Math Utterances and Percentage

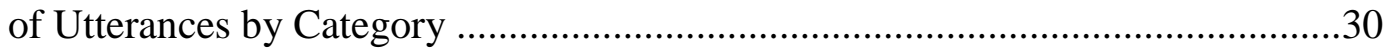

$5 \quad$ Mean Math Utterances, Standard Deviations, and $p$ Values for Each Math Category, Compared by Gender

6 Mean Math Utterances, Standard Deviations, and $p$ Values for Each Math Category, Compared by Age ...................................................... 32

$7 \quad$ Mean Results of Children's Utterances for Teacher Education

Combined with Teacher Experience Comparison ..............................................34 


\section{LIST OF FIGURES}

$\begin{array}{lll}\text { Figure } & \text { Page }\end{array}$

$1 \quad$ Frequency of math utterances for all children

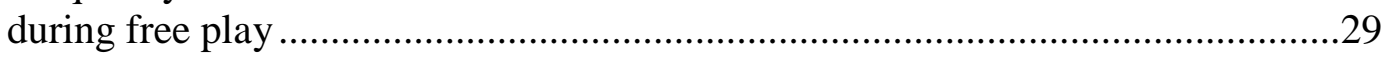

2 Frequencies of math utterances by children per math category.............................31

3 Mean utterances for all programs when provider

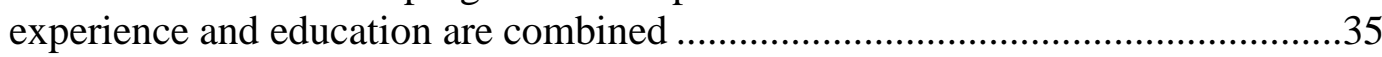




\section{CHAPTER I INTRODUCTION}

Early mathematics concepts are an important element of school readiness and school success. At the same time, children's skills in mathematics appear to be critically deficient as evidenced by a recent report by the National Mathematics Advisory Panel (NMAP, 2008). According to the panel, mathematical skills are the foundations of careers in "science, technology, engineering, and mathematics (STEM)" (NMAP, 2008,

p. 2). Without a good foundation in math skills, future math sophistication needed may be lacking for STEM-type employment. The foundations for mathematics proficiency are laid during the early childhood years (NMAP, 2008).

As of 2001, $60 \%$ of U.S. children under the age of 6 , who were not in kindergarten, were receiving at least once a week some kind of non-parental child care, education, or both (Mulligan, Brimhal, West, \& Chapman, 2005). The time spent in these types of non-parental care averaged between 18 hours per week for children of unemployed mothers and 38 hours per week for children of full-time employed mothers (Mulligan et al., 2005).

As more children have spent an additional amount of time in non-parental care, there has been an extra focus on the experiences children have in these settings. In particular, there are significant concerns that the experiences children have in nonparental care adequately prepare children for school entry and successful school experiences, including skills in mathematics. Keeping these necessary mathematical 
foundations and skills in mind, this study focuses on young children's references to mathematical concepts during free-play activities.

\section{Theoretical Framework}

This study is based on elements from Lev Vygotsky's sociocultural theory (Berk \& Winsler, 1995; John-Steiner \& Mahn, 1996). Vygotsky theorized that an individual's construction of knowledge is developed through "socially shared activities" with others (John-Steiner \& Mahn, 1996, p. 192). As an individual has consistent cooperative experiences, s/he then translates external activities into internalized processes. In other words, as a child interacts with others on any given activity, s/he gains knowledge through social interaction and begins to construct his/her own knowledge based upon those interactions. Vygostky theorized that as a child begins to learn new concepts, s/he relies on intermental activities with more experienced individuals for concept development until s/he becomes proficient enough to initiate intramental and intermental expressions of the concept her/himself (John-Steiner \& Mahn, 1996). This process has been termed as guided participation (Rogoff, 1990).

Relevant to this study is the role that language plays in development (Vygotsky, 1978). Vygotsky suggested that young children's speech is "as important as the role of action in attaining the goal...speech and action are part of one and the same complex psychological function" (p. 25). In other words, children use language as a tool when

they are acting out various functions and roles. Vygotsky further suggested that children use their language abilities to help them solve tasks, which not only "facilitates the 
child's effective manipulation of objects," but speech also helps children shape their own behavior (p. 26). In so doing, young children use speech to move concepts introduced externally to an internal level. In that sense, children's speech indicates those concepts they are exploring and working to internalize. In this study, evidence of children's mathematics concepts was examined including (a) classification, (b) magnitude, (c) enumeration, (d) pattern and shape, (e) spatial relations, and (f) part/whole relations as expressed during free-play with a peer, the child care provider, or by oneself.

\section{What Is Known?}

Levine, Suriyakham, Rowe, Huttenlocher, and Gunderson (2010) studied 44 children between 14 and 30 months and how often they heard math talk from their primary caregivers (parents) and how this related to their understanding of cardinality (i.e. hearing the word 'three' means that there are 3 items). They found that the more math words the children heard from their parents (this included actual number words and references to how to use numbers, like 'count' and 'how many'), the better their understanding of cardinality at 46 months old.

In prekindergarten settings, the authors of one study related that children spend most of their time in free-choice activities (27\%; Chien et al., 2010, p. 1540). In the same study, the authors reported that the time spent in mathematics activities constituted $8 \%$ of children's preacademic and academic activities. Given the importance of mathematics to cognitive development, this might seem like a small percentage of time spent on developing those concepts. 


\section{What Is Not Known?}

It is not known, however, how much time children spend discussing mathematical concepts during their free play; and given that conceptual development involves discussion between individuals, this is an important variable to examine. Free play is a prominent part of a child's daily experiences, and the discussions during free play might be representative of the real-world concepts children feel comfortable using to make sense of their world.

Although there is at least one previous study found that analyzed the time that children spend referencing math in their daily activities (Ginsburg, Lin, Ness, \& Seo, 2003), no other studies have been found that addressed this issue. Analyzing the time that is used in didactic situations for mathematical instruction is useful, but it would also be beneficial to further analyze how children reference math during their free-play activities as a possible indication of their internalization of the concepts. Looking at speech during free-play time would allow researchers to understand how children use math in social activities and how often it is used to structure their play. If children are found to consistently reference certain mathematics concepts during free play, these vocalizations would likely indicate the concepts they are attempting to understand and internalize. To date, very little is known about the way children spontaneously incorporate mathematical themes into their free-play activities. Such an investigation will help those interested in child development understand children's growing mathematical knowledge and will provide an important point of reference for providers when working to help children develop mathematics concepts. 


\section{Purpose of the Study}

This study analyzed the math talk that children engage in during free play in their non-parental, family child care environments. The researcher investigated different types of math reference in the literature. After discussing the options with math and child development scholars (see Blevins-Knabe, Austin, Musun, Eddy, \& Jones, 2000), the researcher decided to use a coding system suggested by Ginsburg and colleagues (Ginsburg et al., 2003). In this study, math talk is defined as any utterance relating to mathematics as defined by Ginsburg and associates. Types of math talk include: (a) classification, (b) magnitude, (c) enumeration, (d) patterns and shapes, (e) spatial reasons, and (f) part/whole. For a complete list of math talk that was analyzed in this study, see Appendices A and B.

\section{Research Questions}

During this study, the following questions were investigated:

1. During free play, how frequently do children in family child care settings engage in math talk? What are the differences between ages and genders?

2. What types of math talk do children in family care settings participate in most: (a) classification, (b) magnitude, (c) enumeration, (d) pattern and shape, (e) spatial relations, or (f) part/whole? What are the differences between ages and genders?

3. To what extent do the education and experience of the providers correlate with the rate of math talk engaged in by children in their care? 


\section{CHAPTER II}

\section{LITERATURE REVIEW}

This chapter reviews the literature on mathematics, focusing mainly on mathematics during the early years. It begins by discussing why skills and knowledge in mathematics are essential. The focus then changes to show the types of instruction used for mathematics in pre-kindergarten in order to gain a better understanding of how mathematics are used in caregiving environments. Finally, the focus shifts to the kinds of play activities in which math conversations are discovered.

\section{Why the Need for Mathematics Skills?}

In its 2008 report, the National Mathematics Advisory Panel (NMAP) reported that the United States (U.S.) is trailing behind other nations in scores associated with science, engineering, medicine, finance, exploration, and other math-related fields. This is the case for all ages. NMAP reported that $32 \%$ of U.S. students are at or above the "proficient level" in $8^{\text {th }}$ grade, and by the $12^{\text {th }}$ grade $23 \%$ are "proficient," a decrease of 9\% in four years (NMAP, 2008, p. xii). Whether it is because of lack of proficiency or lack of interest, there has been a decrease of U.S. residents going into math-related fields. NMAP reported that the U.S. has imported "a great volume of technical talent from abroad," ranging between $14 \%$ and $22 \%$ in the technical workforce and up to $38 \%$ of workers at the doctoral-level positions (p. 2). NMAP has called for higher levels of mathematic skills from U.S. residents in order to fill the science, technology, engineering, and mathematics (STEM) fields. Available positions in these fields, specifically science 
and engineering, tripled during the 90s (National Science Board, 2008). NMAP stated that with the growth in STEM-related fields, combined with retirements, there will be a significant strain on the ability of the U.S. to fill future positions (NMAP, 2008).

The National Science Board has associated the lack of preparation for these types of jobs on the education of students. The educational foundation provided via school instruction have not yielded the necessary number of U.S. students for jobs in STEMrelated fields (National Science Board, 2008). NMAP has declared that there is a growing need for "remedial mathematics" classes for new students at colleges, both community and four-year, around the U.S. (2008, p. 4). Although there has been an increase of high school students completing mathematics courses in the last 10 years (National Science Board, 2008), a 2007 study, looking at math literacy and problemsolving, found that U.S. 15-year-olds ranked $25^{\text {th }}$ out of the 30 developed nations tested (Baldi, Jin, Skemer, Green, Herget, \& Xie, 2007).

The lack of mathematics-related skills shows at even earlier ages than high school. Even with the high percentage (92\%) of fifth-graders who could complete simple multiplication and division problems, only $43 \%$ were able to solve word problems with measurement and rate, and $13 \%$ could solve word problems that used fractions (National Science Board, 2008, pp. 1-7). In addition, another study found that $7 \%$ of U.S. fourthgraders, compared to $38 \%$ of Singapore fourth-graders, scored at an advanced level on the 2007 Programme for International Student Assessment (PISA; NMAP, 2008, p. 4). Uneven proficiencies in mathematics skills have even been found for earlier ages: during the preschool years. Poor mathematics skills have been documented for low 
income (Lee, Autry, Fox, \& Williams, 2008), low SES children (e.g., Jordan, Kaplan, Locuniak, \& Ramineni, 2007; Klibanoff, Levine, Huttenlocher, Vasilyeva, \& Hedges, 2006; Lee \& Burkam, 2002), and for some middle SES children as well (Lee \& Burkam, 2002). If children are entering formal schooling with inadequate mathematics skills, attention to the development of early mathematics skills must begin earlier than might be expected. Since preschool children learn through play, a natural first step is to determine which mathematics concepts are incorporated into play themes.

In summary, the need for mathematical skills in the workforce is widespread. The educational venue, while seeing gains in assessments over the past few years, has not yet produced the needed expertise to fulfill the requirements for STEM-related positions in the U.S. It is widely known that the foundation for all academic skills is laid during the preschool years, the developmental period on which this study is focused (for example see Shonkoff \& Phillips, 2000).

\section{Mathematics Instruction in Pre-kindergarten}

Mathematics has been reported as low on the list of activity and teaching priorities by some family home day care providers (Blevins-Knabe et al., 2000; Phillips \& Morse, 2011). In the Blevins-Knabe et al. study (2000), math activities occurred more often in caregiving environments than in the home, but the providers surveyed responded that math activities usually happened less than once a day in their respective programs (Blevins-Knabe et al., 2000). Phillips and Morse (2011) surveyed 188 home care providers and asked them what they believed to be the most important learning activity to 
provide. Math activities (including math reasoning, math attribute, and number sense) were included on the list along with social skills activities and literacy activities. Of the 12 activities offered, math activities were, on average, rated to be behind the literacy activities. Literacy activities took the first three slots, taking precedence over the mathematical activities that were rated fourth through eighth. Although math activities were considered essential in this study, these types of activities fell behind literacy in importance.

Ginsberg and colleagues (2003) suggested that "everyday mathematics is untaught" (p. 236) and that most adults, parents and/or teachers, do not realize that math is a part of the child's day. Blevins-Knabe et al. (2000) also found this to be true when care providers and parents could not accurately select, from a provided list, which types of activities included math. Care providers $(N=30)$ and parents $(N=54)$ were asked to note how many times a certain activity happened at day care or at home. They were then asked which of these activities would help teach math. The majority of the providers and parents were more likely to select activities where math was explicitly used, like giving guidance on counting objects $(1,2,3)$, or helping children count past 10 . Few recognized that activities that included sorting shapes, learning a phone number, or showing addition or subtraction with props might be considered mathematical activities.

This does not mean that mathematics is not a part of a child's day when they are enrolled in a caregiving setting. The caregivers and parents may not recognize mathematical teaching opportunities, but children can still learn math skills. Ginsburg et al. (2003) stated that "the acquisition of young children's everyday mathematics is a 
constructive process guided by biological endowment, physical environment, and culture" (p. 236). Do children come ready to learn math because of their biological endowment, and is this enhanced by what their environment (caregiving or home) provides to scaffold their learning (for example, see Shonkoff \& Phillips, 2000)? These opportunities can include the overt ones offered by caregivers (i.e., counting the days of the month during group time), but it can also include covert and unintended opportunities provided (i.e., offering props for children to use where they engage in math activities on their own).

There are caregivers who do offer mathematical activities to enhance the learning environment they provide. Many of these activities are provided secondarily during other learning experiences. The teachers can then offer input relating to math during any type of activity. Klibanoff and colleagues (2006) found a wide range of mathematical input provided by caregivers and teachers to their 4-year-olds. Of the 26 classrooms observed, the input offered by teachers ranged from 1 to 104 times during the hour observed, with the average being $28.3(S D=24.2)$ instances of input (pp. 64-65). There was also a wide variety of types of input offered to the children. Out of the possible nine types of input coded, all nine were used by the teachers with the average being $3.9(S D=1.8)$. The nine types of input included: (a) counting; (b) cardinality (saying a number); (c) equivalence (i.e., saying equal); (d) nonequivalence (contradicting what the child stated); (e) number symbols (when working with written figures); (f) conventional nominative (using numbers in titles or names); (g) calculation; and (h) placeholding, or referring to a place 
value (i.e., ones, tens, hundreds). When correlations were run, results showed that when teachers offered more input, they also offered more variety in their input.

Tudge (2009), when discussing varying methods for assessing children's math experiences, commented that when educators and caregivers draw attention to math in everyday activities, “the children's understanding of mathematical principles would be enhanced" (p. 4).

\section{Play Activities and Math}

Free play activities often take a substantial part of a day in any type of caregiving environment. It is during free play where children can act out much of what they know and are learning. Play is how children "tend to tackle difficult problems" (Clements \& Sarama, 2005, p. 38). They often use self-speech to help them gain a greater understanding of concepts they previously saw (Vygotsky, 1978). Copley (2000) suggested that children use their experiences "with their environment, their interactions with adults and other children, and their daily observations" to construct their ideas (p. 4). McLellan (2010) arranged a small pilot study with six children who were paired with an educator who provided play opportunities based on math. She found that children used play to connect and solidify math concepts.

Tudge and Doucet (2004) observed 39 three-year-olds for 20 hours over 1 week during their normal activities (child's home, childcare center, other home, and public place). About $15 \%$ of the total observations took place in childcare centers. The researchers found that the children, on average, became involved in some type of 
mathematical activity in the childcare centers about once per hour. They also found that many of the observed children, $60 \%$, never became involved in a mathematical activity. This could be because the caregivers themselves were not aware of opportunities for mathematic engagement (Blevins-Knabe et al., 2000).

When children do engage in mathematics during activities, the math is often secondary to the main activity in which they participate (Tudge, 2009). For example, a child may engage in an activity where they are racing cars with a friend. The child realizes that the cars are different sizes and says, "My car is bigger than your car." The other child may say, "Well, I have two cars and you only have one. So mine are better." This could go many rounds with them trying to compare and outdo each other. In the pilot study by McClellan (2010), the educators used play activities, such as making airplanes, to help enhance learning mathematical concepts. It is often through play that mathematics skills emerge (Sarama \& Clements, 2005).

\section{Early Mathematics Concepts}

Ginsburg et al. (2003) extensively studied 4- and 5-year-old American and Chinese children and how they use, reference, and understand math during their free play activities. The researchers found that there were six main categories that the children used: (a) classification, (b) magnitude, (c) enumeration, (d) pattern and shape, (e) spatial relations, and (d) part/whole concepts. Classification concepts include children engaging in the "systematical arrangement of groups according to clear criteria" (Ginsburg et al., 
2003, p. 243). An example of this would be a child sorting blocks into groups based on shape.

Magnitude is used when a child uses phrases to compare two or more items, "to evaluate relative magnitude" (Ginsburg et al., 2003, p. 243); examples are phrases like, “a lot" or "more higher."

Enumeration is when a child uses "numerical judgment or quantification" (Ginsburg et al., 2003, p. 243). An example of enumeration would be a child saying the number three.

References to dynamics happen when a child relates concepts to the "process of change or transformation" (Ginsburg et al., 2003, p. 243). An example of this would be when a child has a pile of three buttons, takes one away and says, "Now I got two. Now I got one. Now I got none" (Ginsburg et al., 2003, p. 243).

Pattern and shape concepts include a child building a tower out of blocks and proclaiming the tower to be in the shape of a square. This could also include a child stating a pattern of blocks being red, black, red, black, and so forth. Spatial relations happen when a child explores "positions, directions, and distances in space" (Ginsburg et al., 2003, p. 243). Examples would include references to over, under, on, around, and so forth.

Finally, the part/whole concept is when a child references something as being part or whole. This concept was added by Blevins-Knabe (see Blevins-Knabe et al., 2000). For additional information on these concepts, see Appendices B and C. 


\section{Audiotaping Free Play}

Tudge (2009), in summarizing the methods available in observing children, stated that having an observer present in a caregiving environment might influence the types of activities the children engage in. Rather than having a physical observer on sight, an audio recording could be used to observe the children. This would greatly enhance the opportunities to examine math references in their natural free play settings, whether they are with another child or by using self-speech. Tudge mentioned that a disadvantage to using audiotapes would be that not all nonverbal experiences are recorded, but as Vygotsky (1978) found, children often use self-speech when learning.

\section{Summary}

The research shows that caregivers often do not provide constructed math opportunities for children. Even though mathematics activities are not offered regularly for children, they still learn math through observations and daily interactions with others. Free-play time is usually when children work through concepts they are learning or have observed.

In this study, children's references of math during their free play were explored by using audiotape observation. The following questions guided the research:

1. During free play, how frequently do children in family child care settings engage in math talk? What are the differences between ages and genders? 
2. What types of math talk do children in family care settings participate in most: (a) classification, (b) magnitude, (c) enumeration, (d) pattern and shape, (e) spatial relations, or (f) part/whole? What are the differences between ages and genders?

3. To what extent do the education and experience of the providers correlate with the rate of math talk engaged in by children in their care? 


\section{CHAPTER III}

\section{METHOD}

This chapter includes the research methodology used during the study. It describes how participants were recruited, the instruments used, and how the data were collected. It also describes the data analysis that was used to answer the research questions.

\section{Definitions}

In this study, math talk is defined as any reference within an utterance by a child or teacher that relates to mathematics. See Appendices A and B for a complete list of types of math references.

Family child care refers to care that is provided for non-familial children in a home owned by the caregiver. The children who enroll in this type of care are usually of varying ages. There are two types of family child care: family child care homes and family child care groups. For the first, family child care homes, there can be one licensed provider for every eight children in their home. The second, family child care groups, needs at least two full-time providers and can care for up to 16 children in the home.

\section{Participants}

The participants for this study were recruited and selected by a previous graduate student for her dissertation (Ota, 2010). Postcards were sent by mail to the 800 licensed providers in four child care regions to recruit for volunteers for a study on verbal 
language in family child care. Because the response was limited to postcards, phone calls were made and researchers spoke to 238 (30\% of the total 800 programs) family child care programs. After hearing the description of the study, 48 (6\% of the 800 programs; $20 \%$ of the number telephoned, or 238) family child care homes volunteered to be part of the program. The original researcher did not justify the low response rate. For a more detailed description of recruitment efforts see the original dissertation (Ota, 2010).

Informed consent was obtained for all care providers. Four children were originally selected from each program to be participants based on the child: (a) having parental informed consent being signed and submitted; (b) attending a family child care program for a minimum of 30 hours per week; (c) being between two- and four-yearsold; and (d) having no obvious or evident (frank) cognitive or linguistic delays.

The mean number of children who attended a program for 30 hours or more per week per program was 7 (range 4-14). In 16 (33\%) of the programs there were four qualified children enrolled in a program. Ten $(21 \%)$ of the programs had an enrollment high enough so as to randomly select two females and two males to participate. In the remaining programs (22 programs or $46 \%$ ), children were non-randomly selected when there were not enough children of one gender (for example, when one female and five males were enrolled in the program, the one female was selected and three males were selected to participate). As shown in Table 1, gender and age were balanced across all programs; each age group had 16 boys and 16 girls (32 per age group x 3 groups $=96$ children). For this study, the number of children's recordings used was 50 ( $n=30$ boys; $n=20$ girls; $N=50)$. The ages ranged from three to five years old $(n=24, \leq 39$ months 
of age, $n=26 ; \geq 40$ months of age). The data from the present study were chosen by Blevins-Knabe (Blevins-Knabe, Hendershot, Ota, \& Austin, 2011) for a presentation at the biennial Society for Research in Child Development conference. For ease of comparison, effort was made to make the size of age groups similar for comparisons. Additional coding and analysis were run for this study.

\section{Data Collection}

A training intervention was provided for providers in the original study. (For an extensive description on the intervention methodology, see Ota, 2010). Digital sound recordings of the selected children were taken pre-intervention, during intervention, and post-intervention. The recordings were collected by LENA DLPs (digital language processors). The recordings were taken during free play time, which included lunch and snack times.

Each child was recorded for a minimum of 30 minutes during each session (3 sessions $x 30$ minutes $=90$ minutes per selected child). To give children an opportunity to transition between previous activities and free play time, the first 10 minutes of each

Table 1

Age and Gender of Children

\begin{tabular}{lrrr}
\hline & $\leq 39$ months of age & $\geq 40$ months of age & \multicolumn{2}{c}{ Total by gender } \\
\hline Females & 14 & 16 & 30 \\
Males & 10 & 10 & 20 \\
Total by age & 24 & 26 & 50 \\
\hline
\end{tabular}


session were discarded. To capture the richest language use, the next 15 minutes of the recording were used for data analysis ( 3 recordings $\mathrm{x} 15$ minutes $=45$ minutes per selected child). The last 5 minutes of the recordings were not used for analyses.

\section{Instruments}

\section{Demographic Information}

Demographic information for providers was collected after they agreed to participate in the original study. The information was gathered by a questionnaire filled out by the providers. The information gathered included: (a) educational level; (b) training hours completed; (c) years of experience; and (d) ages of children in care.

Once children and parents had fulfilled the basic requirements (listed under the section "Participants"), demographic information was collected for the children. The information was gathered by questionnaires that parents filled out. The gathered information about participating children was (a) age (in months) and (b) gender.

\section{LENA}

The LENA (LENA Foundation, 2011) is a tool for automatic speech recording and analysis. In order to record the children's speech, a small digital recorder, a digital language processor (DPL), was placed in the pocket of a T-shirt that was specially designed for studies such as this. The DPL weighed approximately 2 oz. and held 16 hours of recorded sound. The LENA software was used to transfer the information from the DPL to a computer. The recordings were broken down into five minute segments for purposes of transcription. The LENA program was used to calculate the total number of 
utterances for each child. Reliability for LENA for adult and child vocalization scores has been found to be between .65 and .92 (Xu, Yapanel, \& Gray, 2009, p. 8).

Additional children in the selected caregiving environments, but who were not selected to be part of the study, were asked to wear t-shirts and similar-looking devices. The speech of these children was not recorded. This was to eliminate any preference that might have been given by the caregiver to those who were wearing the actual DPL recorders.

\section{Coding System/NVivo}

The coding system used, as seen in Appendix C, was based on a coding scheme that was created and implemented by Ginsburg, Klein, and Starkey (1998) and was revised in 2003 (Ginsburg et al., 2003) in a study comparing 4- and 5-year-old American and Chinese children's math activities during free play. Blevins-Knabe et al. (2000) used this scheme in previous studies. Additions and changes were made by Blevins-Knabe in order to provide clearer concepts in differences between categories for the coders (for example, subcategories were created so that all math words had clear categories to be coded into).

Transcriptions, shown in Appendix D, were made of the recordings and uploaded to NVivo. The transcripts were grouped by caregiving facility and child. NVivo (QSR International, 2011), version 9, was used to target math references in the transcriptions. NVivo is a qualitative program that can search documents for key words or phrases. The program also has the capability to store selected words or phrases into different categories or codes. 
The researcher attended a two-day NVivo training in San Fransisco. The intensive training consisted how to use NVivo to: (a) upload documents in preparation of coding, (b) set up codes, (c) create queries (searches), (d) code documents using queries, and (e) use queries to compute frequencies.

After the tapes were transcribed and uploaded to NVivo, the researcher reread the transcript dialogues to note whether the child was playing or if the situation was geared more towards teaching (i.e., circle time), directives to cleanup, or a teacher reading to the child. If the transcript was found to offer more teaching, directives to clean, or a teacher reading to the child, it was not coded for math references, but was considered to be a 'teaching' transcript. If the transcript was considered as teaching, cleanup, or reading, but there was more conversation (give and take) between teacher and child than directives and/or reading, it was coded for math references.

The researcher used NVivo to search for math words and phrases used by the children, caregivers, and other children in the program. Once the math words or phrases were targeted, the researcher stored or saved them in the desired code/category. The following math codes were used: (a) classification, (b) magnitude, (c) enumeration, (d) pattern and shape, (e) spatial relations, and (f) part/whole. Magnitude, enumeration, pattern and shape, and spatial relations had sub-codes to break down particular types of references. For a complete list of codes and definitions of codes see Appendices A and B. For an example of a coded transcript, see Appendix E.

The references that were coded as spatial relations were done so carefully. The coder read the context that the reference was used in to make sure that the word was 
actually a spatial relation preposition rather than a regular preposition. For example, the statement, "I am on my way" would not be coded as a spatial relation reference because it was not used to denote a position, direction, or distance in space.

A code was assigned to the type of context the target child was in during the free play activity. The following were the possible contexts: (a) with other child only; (b) with teacher only; (c) alone; or (d) with other child and teacher (all).

\section{Pilot Data}

A pilot study was conducted by Blevins-Knabe, Berghout Austin, and the researcher. Each looked at eight to ten printed transcripts and coded references according to the coding system by Ginsburg et al. (2003). After the initial coding, several adjustments to the coding system were made by Blevins-Knabe. Extra subcodes were created for enumeration (i.e., all, number one identifier, time) and spatial relations (i.e., on, around, under, up). One additional code, part/whole, was also added. The researchers decided to use NVivo in order to standardize the utterances each coder would examine. The pilot data were recoded using NVivo (as explained in the previous section).

\section{Interrater Reliability}

In the pilot study, interrater reliability was problematic. There were issues on two different levels. First, it was unclear which references to code as mathematics references, particularly with regard to spatial relations, shown as \#5 on the coding scheme in Appendix B (i.e., in, around, on, above). Second, the researchers achieved a low level of 
reliability when coding the actual words themselves. The decision was made to use NVivo. This helped target the coding to specific words and phrases.

Interrater reliability was figured by math code per transcript. Reliability was figured at 20\% intervals. The researcher and Blevins-Knabe separately coded for 12 of the 50 children in this study. NVivo has the capability to merge the separately coded documents and provide an 'agreement' (interrater reliability) figure. This figure was the percentage of matching codes. The range for agreement was $85 \%$ to $99 \%$ (the agreement values increased as more coding was completed). When there was uncertainty about coding, the researchers consulted with each other to resolve the questions.

\section{Data Analyses}

As stated in a previous chapter, the following research questions were investigated:

1. During free play, how frequently do children in family child care settings engage in math talk? What are the differences between ages and genders?

2. What types of math talk do children in family care settings participate in

most: (a) classification, (b) magnitude, (c) enumeration, (d) pattern and shape, (e) spatial relations, or (f) part/whole? What are the differences between ages and genders?

3. To what extent do the education and experience of the providers correlate with the rate of math talk engaged in by children in their care? 


\section{Question 1 Analyses}

To answer question 1, frequencies were run on how often the children reference math during their free play. To do this, the total number of utterances by the target child were figured and recorded (this included all nine recordings per target child). Next, the total number of math references used by the target child was calculated and recorded (this also included all nine recordings per target child). The total number of math references was calculated by the researcher using NVivo as a search tool. The total number of math references was divided by the number of total utterances. This showed the percentage (mean) of free-play time the target children used in referencing math.

Differences between genders were calculated. This was done by using the total percentage of math references for each child and grouping them into groups based on gender. A $t$ test was used to calculate the difference between the two groups to see if males or females reference math more during their free play.

Differences between age groups were also calculated. Age was split into two equal categories: (a) 39 months and younger (3 1/4 years old and younger); or (b) 40

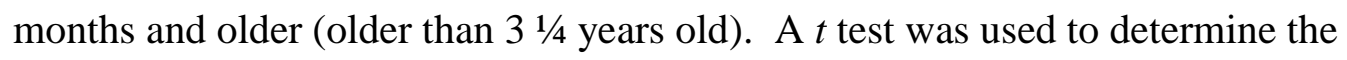
differences between the two age groups.

\section{Question 2 Analyses}

Question 2 was first analyzed by running frequencies for each of the six categories. This was done by calculating the total sum of references per category for all of the target children. The sum for each category was then divided by the total summation of math references for all six categories, giving a mean for each category. 
Differences between genders were figured for each math category. To do this, the mean of math references was used for each child per category. They were assigned into groups based on gender. A $t$ test was used to calculate the difference between the two groups for each math category to see if males or females reference the category of math more during their free play.

Differences between the two age groups were then calculated for each math category. A $t$ test was used to determine the differences between the two age groups for each category.

\section{Question 3 Analyses}

In order to calculate the relationship between math talk and (a) the education of the provider, and (b) the experience of the provider, a 3 (education level) $x 2$ (experience) ANOVA was used. For ease of analysis, the education was divided into three levels: (a) high school; (b) child development associate credential (CDA) or 2-year degree; and (c) 4-year degree or graduate degree. These levels indicated the education achieved by the provider. The experience of the provider was shown by referencing how many years the provider had worked in childcare. For ease of analysis, the experience of the provider was divided into two categories: (a) less than 10 years and (b) more than 10 years.

Table 2 shows the breakdown of the number of children by age and gender according to each category for provider education.

Table 3 shows the division of children by gender and age according to the experience of the provider. 
Table 2

Children Divided by Age and Gender According to the Education of the Provider

\begin{tabular}{lrrrr}
\hline & $\begin{array}{c}\text { High } \\
\text { school }\end{array}$ & $\begin{array}{l}\text { CDA or 2-year } \\
\text { degree }\end{array}$ & $\begin{array}{l}\text { 4-year or } \\
\text { graduate degree }\end{array}$ & \multicolumn{2}{c}{ Total by age } \\
\hline Females $\leq 39$ mo & 5 & 4 & 5 & 14 \\
Females $\geq 40$ mo & 3 & 4 & 9 & 16 \\
Males $\leq 39$ mo & 2 & 2 & 6 & 10 \\
Males $\geq 40$ mo & 0 & 6 & 4 & 10 \\
Total by education & 10 & 16 & 14 & \\
\hline
\end{tabular}

Table 3

Children Divided by Age and Gender According to the Experience of the Provider

\begin{tabular}{lrrr}
\hline & $<10$ Years' experience & $>10$ Years' experience & Total by age \\
\hline Females $\leq 39$ mo & 10 & 4 & 14 \\
Females $\geq 40$ mo & 8 & 8 & 16 \\
Males $\leq 39$ mo & 5 & 5 & 10 \\
Males $\geq 40$ mo & 5 & 5 & 10 \\
Total by experience & 28 & 22 & \\
\hline
\end{tabular}

A chi-square and ANOVA were used to compare the main effects and interactions relative to the total math references for the two target children from their program. The ANOVA was run three different times to compare: (a) the total math references for the low scoring child in the program; (b) the total math references for the high scoring child in the program; and (c) the average of math references for the two children in the program. Since there were no statistically significant differences between the low and high scoring child per program, the scores were collapsed to show only the average 
comparison. Because there were no statistically significant differences in previous analyses, age and gender were not considered during this analysis.

The chi-square was used to compare the high scoring child against the low scoring child of the program comparing their (a) total math references and (b) math scores in reference to the provider education. 


\section{CHAPTER IV}

\section{RESULTS}

Data were first entered into Excel and then double checked by the author. The data were then converted into SPSS. All analyses were done using SPSS 17.0 and 19.0.

Statistical power was calculated ad hoc at .41. This means that if there were any significant findings to be found, there would be a $41 \%$ chance of discovering those findings in the sample used.

\section{Question 1}

During free play, how frequently do children in family child care settings engage in math talk? What are the differences between ages and genders? As shown in Figure 1, the distribution of how frequently children referenced math during free play was positively skewed $(M=41.44, S D=28.53$, range $=2-118)$. Most children referenced math between 5 and $10 \%$ of the time when they spoke.

There were 30 male children and 20 female children in the sample. The mean math utterances for males was $12.88(S D=5.9)$. The mean math utterances for females was $14.54(S D=11.99)$. Females used math language more frequently in their speech, but the difference was not statistically significant $(t=-.65, p=.52)$.

Children were split into two age groups. The younger group $(n=24)$ was 39 months or younger ( $\leq 4$ years and 3 months). The older group $(n=26)$ was 40 months or older ( $\geq 4$ years and 4 months). The mean math utterances for those who were 39 months or younger was $12.21(S D=10.36)$. The mean math utterances for those 40 months and 


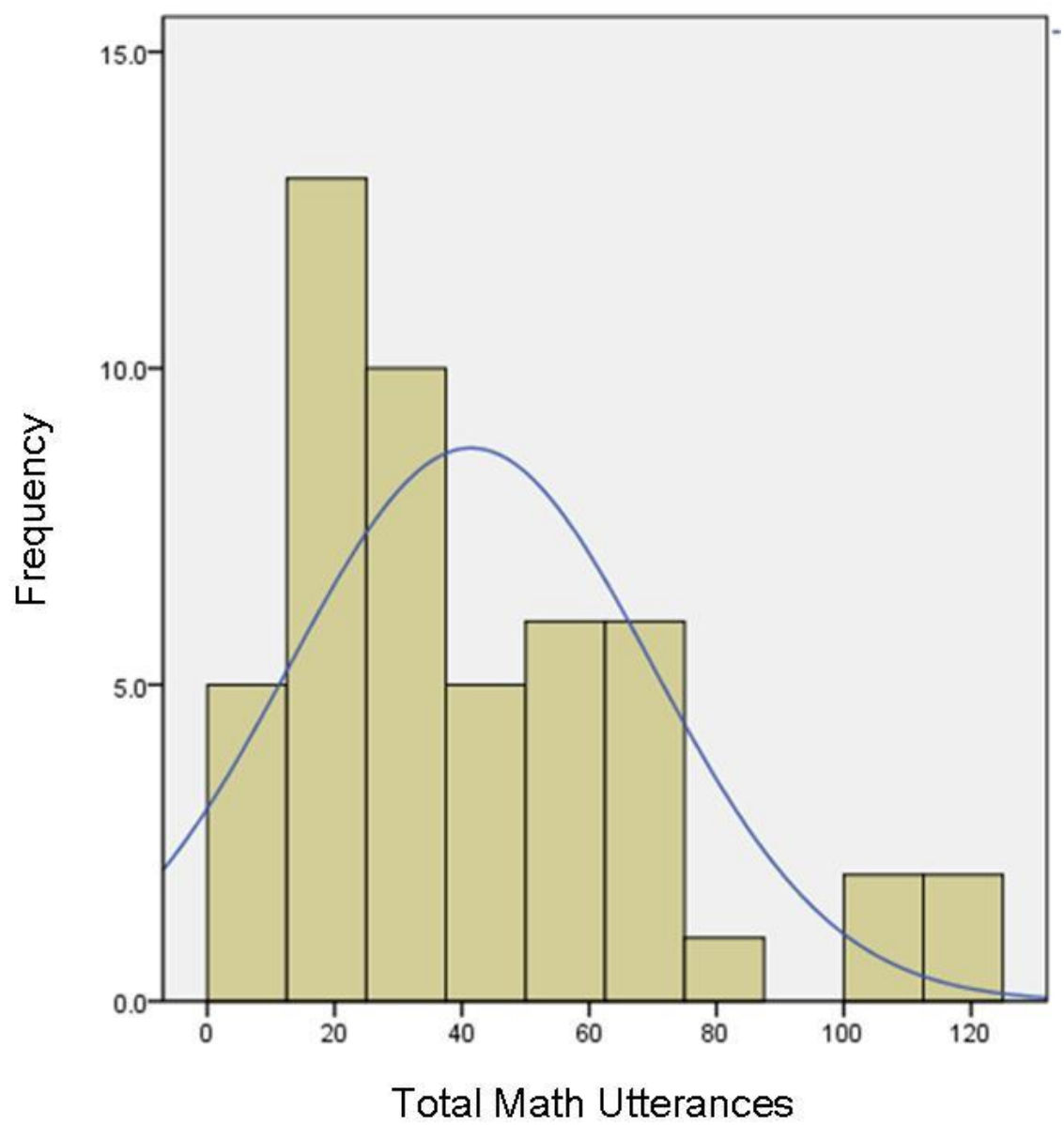

Figure 1. Frequency of math utterances for all children during free play.

older was $14.78(S D=7.03)$. Those children who were 40 months or older referenced math more during their speech, but the difference was not statistically significant $(t=$ $-1.03, p=.31)$.

\section{Question 2}

What types of math talk do children in family care settings participate in most: (a) classification, (b) magnitude, (c) enumeration, (d) pattern and shape, (e) spatial relations, or (f) part/whole? What are the differences between ages and genders? There were 
15,886 total utterances for all 50 children. Math was referenced 2,074 times, or $13.06 \%$ of the time, for all children during free play activities.

As shown in Table 4 and Figure 2, of the 2074 math references, spatial relations were referenced most frequently at $48.60 \%$ of the time $(n=1,008)$; enumeration was referenced second most frequently at $34.38 \%(n=713)$; magnitude was third in the times it was referenced at $15.91 \%(n=330)$; part/whole references were made $.72 \%$ (less than $1 \%)$ of the time $(n=15)$; pattern references were used $.39 \%$ (less than $1 \%)$ of the time ( $n$ $=8)$; and classification references were not made at all $(n=0)$.

As shown in Table 5, males referenced magnitude $(M=7.53, S D=6.74)$, enumeration $(M=14.73, S D=12.43)$, spatial relations $(M=21.73, S D=15.78)$, and part/whole $(M=.33, S D=.84)$ more often than females, although none of the results were statistically significant at $p<.05$. Females referenced one category more than males, pattern/shape $(M=.20, S D=.43)$, but the result was not statistically significant at $p<.05$.

Table 4

Number of Math Utterances and Percentage of Utterances by Category

\begin{tabular}{lrr}
\hline Math category & Number of math utterances & Percentage of math utterances \\
\hline 1-Classification & 0 & 0 \\
2-Magnitude & 330 & 15.91 \\
3-Enumeration & 713 & 34.38 \\
4-Pattern/shape & 8 & 0.39 \\
5-Spatial relations & 1008 & 48.60 \\
6-Part/whole & 15 & 0.72 \\
TOTAL & 2074 & 100 \\
\hline
\end{tabular}




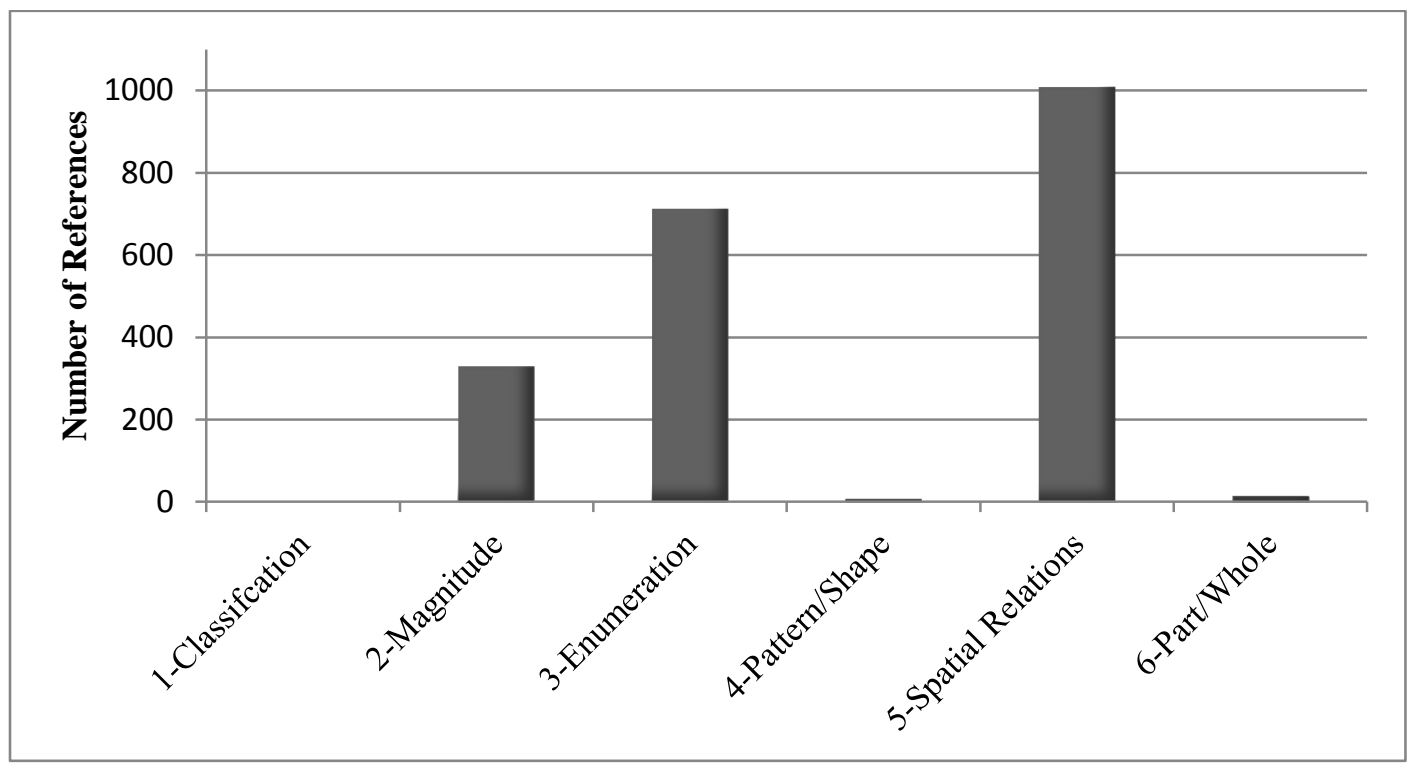

Figure 2. Frequencies of math utterances by children per math category.

Table 5

Mean Math Utterances, Standard Deviations, and p Values for Each Math Category, Compared by Gender

\begin{tabular}{|c|c|c|c|c|c|}
\hline Math category & Gender & Mean utterances & $\begin{array}{l}\text { Standard } \\
\text { deviation }\end{array}$ & Range & $p$ value \\
\hline \multirow[t]{2}{*}{ 1-Classification } & Male & .00 & .00 & 0 & N/A \\
\hline & Female & .00 & .00 & 0 & \\
\hline \multirow[t]{2}{*}{ 2-Magnitude } & Male & 7.53 & 6.74 & 0 to 18 & .210 \\
\hline & Female & 5.20 & 5.72 & 0 to 26 & \\
\hline \multirow[t]{2}{*}{ 3-Enumeration } & Male & 14.73 & 12.43 & 1 to 39 & .727 \\
\hline & Female & 13.55 & 10.43 & 0 to 42 & \\
\hline \multirow[t]{2}{*}{ 4-Pattern/shape } & Male & .13 & .43 & 0 to 2 & .626 \\
\hline & Female & .20 & .52 & 0 to 2 & \\
\hline \multirow[t]{2}{*}{ 5-Spatial Relations } & Male & 21.73 & 15.78 & 0 to 42 & .359 \\
\hline & Female & 17.80 & 12.90 & 1 to 75 & \\
\hline \multirow[t]{2}{*}{ 6-Part/whole } & Male & .33 & .84 & 0 to 3 & .727 \\
\hline & Female & .25 & .79 & 0 to 3 & \\
\hline
\end{tabular}


Table 6 shows the results of the $t$ test analysis between ages and how frequently math was referenced. Those children who were 39 month or younger referenced one category more than the children who were 40 months or older, pattern/shape $(M=.21, S D$ $=.59$ ), but the result was not statistically significant at $p<.05$. Children who were 40 months or older referenced math more using magnitude $(M=7.96, S D=6.73)$, enumeration $(M=15.50, S D=10.73)$, spatial relations $(M=24.54, S D=15.35)$, and part/whole $(M=.35, S D=.80)$ utterances. The result for spatial relations was the only category to reach statistical significance at $p<.027$. All other results for references by age were not statistically significant.

Table 6

Mean Math Utterances, Standard Deviations, and p Values for Each Math Category, Compared by Age

\begin{tabular}{|c|c|c|c|c|c|}
\hline Math category & Gender & $\begin{array}{l}\text { Mean } \\
\text { utterances }\end{array}$ & $\begin{array}{l}\text { Standard } \\
\text { deviation }\end{array}$ & Range & $p$ value \\
\hline \multirow[t]{2}{*}{ 1-Classification } & $\leq 39 \mathrm{mo}$ & .00 & .00 & 0 & None \\
\hline & $\geq 40 \mathrm{mo}$ & .00 & .00 & 0 & \\
\hline \multirow[t]{2}{*}{ 2-Magnitude } & $\leq 39 \mathrm{mo}$ & 5.13 & 5.79 & 0 to 18 & .118 \\
\hline & $\geq 40 \mathrm{mo}$ & 7.96 & 6.73 & 0 to 26 & \\
\hline \multirow[t]{2}{*}{ 3-Enumeration } & $\leq 39 \mathrm{mo}$ & 12.92 & 12.51 & 0 to 40 & .436 \\
\hline & $\geq 40 \mathrm{mo}$ & 15.50 & 10.73 & 2 to 42 & \\
\hline \multirow[t]{2}{*}{ 4-Pattern/shape } & $\leq 39 \mathrm{mo}$ & .21 & .59 & 0 to 2 & .488 \\
\hline & $\geq 40 \mathrm{mo}$ & .12 & .33 & 0 to 1 & \\
\hline \multirow[t]{2}{*}{ 5-Spatial relations } & $\leq 39 \mathrm{mo}$ & 15.42 & 12.58 & 0 to 42 & .027 \\
\hline & $\geq 40 \mathrm{mo}$ & 24.54 & 15.35 & 1 to 75 & \\
\hline \multirow[t]{2}{*}{ 6-Part/whole } & $\leq 39 \mathrm{mo}$ & .25 & .85 & 0 to 3 & .681 \\
\hline & $\geq 40 \mathrm{mo}$ & .35 & .80 & 0 to 3 & \\
\hline
\end{tabular}

\section{Question 3}


To what extent do the education and experience of the providers correlate with the rate of math talk engaged in by children in their care? Providers were first split into two categories based on their experience. Group $1(n=28)$ had 10 years or less of experience. Group $2(n=22)$ had 10 years or more of experience. For the children whose providers were in group 1, their mean math references was $39.29(S D=23.99)$. For children whose provider were in group 2, their mean math references was 44.18 ( $S D$ $=33.83)$. The results were not significant $(t=-.598, p=.26)$.

Next, the providers were divided into three categories based on their education as follows: (a) high school; (b) child development associate credential (CDA) or 2-year degree; and (c) 4-year degree or graduate degree. For Category A $(n=10)$, mean references of children equaled $36.90(S D=28.98)$. For Category B $(n=16)$, mean references of children equaled $49.44(S D=29.11)$. Category $\mathrm{C}(n=24)$ mean references of children equaled $38.00(S D=28.04)$. Children whose providers had a CDA or a 2year degree, Category B, (the practical degrees) referenced math more frequently during free play, although the difference was not statistically significant $(F=.927, p=.40)$.

A chi-square test was run to compare the high scoring child in a program to the low scoring child in the same program, based upon their total math utterances. The mean differences were compared in reference to provider experience. There was no statistically significant comparisons between the two groups $(p=1.0)$.

A chi-square test was also run to compare the high and low scoring children in reference to the provider education. There were no statistically significant differences between the groups $(p=.46)$. 
A 3x2 ANOVA was run to assess mean differences of the total math utterances for all children (combining high scoring and low scoring children) when comparing provider education (3 levels) and provider experience (2 levels). Figure 3 and Table 7 show the results of the ANOVA. The children in programs where the providers had more than 10 years' experience reference math more than children in programs where the providers had less experience. As seen in Figure 3, children who were in programs where the providers had a CDA or a 2-year degree (practical degrees) referenced math more than the children in other programs. However, these results showed no statistical significant differences $(F=.68, d f=2, p=.94)$.

Table 7

Mean Results of Children's Utterances for Teacher Education Combined with Teacher Experience Comparison

\begin{tabular}{|c|c|c|c|}
\hline & $\begin{array}{l}\text { Number of } \\
\text { providers }\end{array}$ & $\begin{array}{l}\text { Experience of } \\
<10 \text { years }\end{array}$ & $\begin{array}{l}\text { Experience of } \\
>10 \text { years }\end{array}$ \\
\hline High school & 10 & 31.17 & 45.50 \\
\hline $\mathrm{CDA} / 2$ yr degree & 16 & 48.08 & 53.50 \\
\hline 4 Yr/graduate degree & 24 & 33.60 & 41.14 \\
\hline
\end{tabular}




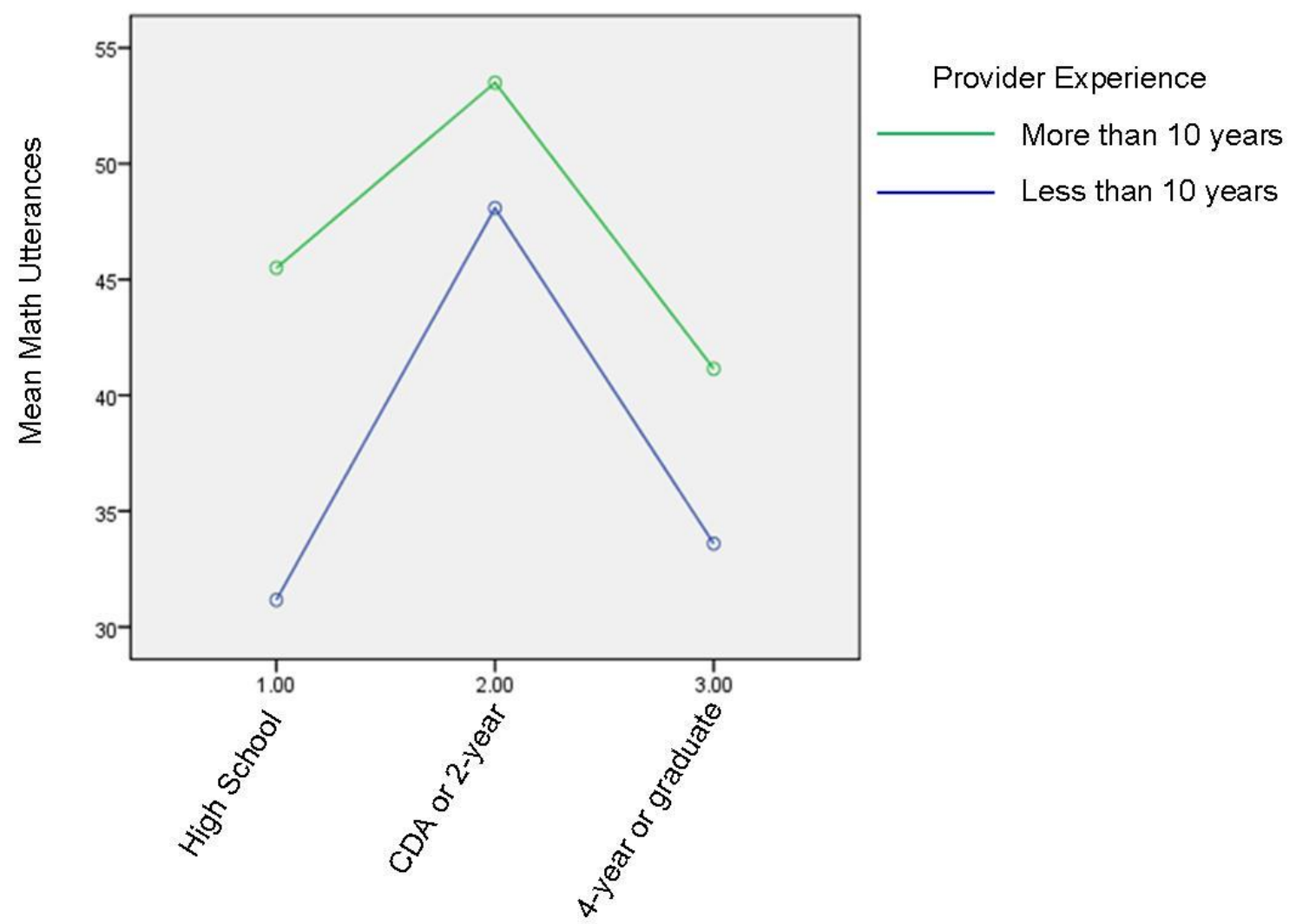

Figure 3. Mean utterances for all programs when provider experience and education are combined.

\section{Summary}

In summary, the one statistically significant finding was that children who were 40 months or older used more spatial relation references in their math language than did children who were 39 months or younger. No other findings were significant.

There was a trend in the analyses that compared children's math references with provider education and experience. When providers had more experience, the children in their care used math references more frequently no matter the education of the provider. 
Also, when the provider had the 2-year degree or CDA (the more practical degrees), the trend showed that children in their care referenced math more frequently. 


\section{CHAPTER V}

\section{DISCUSSION}

Vygotsky (1978) believed that language is a tool that children use when they act out various functions and roles. Children use language in all of their activities, especially during free play when they are allowed to freely act out games or discuss their actions. This study supports these claims in that children used speech often during their free play. The children in this study used math in $17 \%$ of their vocal interactions during free play. Math was used to count, to reference spatial relations, to help understand whether something was large or small, and to designate shapes and patterns. Children used math when talking to themselves, to other children, and to their teachers showing that they were not hesitant to share what they knew or to ask questions about things they were unsure of. It seems that free play is a good time to use mathematical references and to enhance basic math knowledge.

\section{Types of Math Talk}

According to the National Math Advisory Panel, "Most children acquire considerable knowledge of numbers and other aspects of mathematics before they enter kindergarten" (NMAP, 2008, p. xviii). When children begin their formal compulsory education, the majority already have basic foundations of math on which to build upon. The results of this study indicate that three- to five-year-olds use math frequently in their activities, particularly their play time. It seems that as children grow older, their use of math becomes more prominent in their activities. Although the types of math used 
during the preschool years are not as numerous as at other ages (NMAP, 2008), they have already begun to understand basic math concepts and how they integrate into their everyday activities.

The purpose of this study was to examine and analyze the math talk that children engage in during free play in their non-parental, family child care environments. Results showed that children used much more spatial relations in their speech than any other type of mathematical concept. Spatial relations are when there is an exploration of positions, directions, and distances in space (Ginsburg et al., 2003; also see Appendix B). Specific examples of spatial relation usage were: (a) Can we get in yet?, (b) I colored on that, (c) I want to sit by her, and (d) I have this blanket to go over you. One possible reason that spatial relations were used most frequently is that teachers are more likely to use these references as part of their normal speech (prepositions), thus influencing the use of spatial relations used by children. Because of the references being part of normal speech, children probably use them with more ease and frequency than other types of math references. Ginsburg, Lee, and Boyd (2008) called these types of references "everyday mathematics" (p. 3) that include "informal ideas" of mathematical concepts. Ginsburg and colleagues stated that these types of mathematics are necessary building blocks to later achievement.

Enumeration was second in frequency of use. Most of the references to enumeration included words that were numbers. Specific examples were: (a) Gotta see my blanky first, (b) You can choose one, and (c) I want that one. (In this case, one is not used to specify a unit of one, but to specify something in particular.) Enumeration was 
second in use most likely because of the regularity of the use of the word 'one' to distinguish which object is being referred to by a child or caregiver (see Appendix B). This subcode was added by Blevins-Knabe (Blevins-Knabe et al., 2011), and it is not clear that this reference has a numerical meaning, but it is used frequently in common speech. Ginsburg and colleagues (2003) did not differentiate between the uses of 'one' in their research.

The other categories of classification, magnitude, pattern and shape, and part/whole concepts were not used as frequently because they are not used as frequently in normal speech. One possible reason that classification has zero references was the way the scheme defined classification, "Systematic arrangement of groups according to clear criteria" (as shown in Appendix B). In order for the researcher to understand that a child is using a systematic arrangement, they would need more than just audio recordings. There would also need to be a video/observation component in order to see what the child is doing. Another reason for low frequencies in these areas is that free play activities may not offer the resources (games, toys, etc.) needed to enhance math references in these categories. Math is specifically used in circle time (Klibanoff et al., 2006), but providers may not be aware of how to provide additional math opportunities during free time.

\section{Provider Education and Experience}

NMAP (2008) stated that there is a relationship between a teacher's math knowledge and a student's math achievement. "It is self-evident that teachers cannot 
teach what they do not know" (NMAP, 2008, p. xxi). The results of this study support this claim. The providers who had more experience in child care, mixed with a practical education, had children in their care who referenced math more frequently in free time play. This suggests that when providers know how to provide opportunities to learn math, whether through education or their own teaching experiences, have children in their care that are more likely to reference mathematics. Also, the findings suggest that when providers go through CDA training or obtain a 2-year degree, they may learn more practical applications of concepts, implying that a 4-year or graduate degree may not be as practical as a CDA or 2-year degree.

\section{Limitations}

There are limitations to this study. The first limitation is that the statistical power was $41 \%$. This means that there was not a great chance of finding significant relations between variables. In future studies, having greater statistical power (more participants) would increase the likelihood of finding significant relationships. If all 96 participants were included in a study, the statistical power would be $.68(68 \%)$, which is still relatively low. In order to receive a desired statistical power score of .80 (80\% chance of discovering significant findings if there are to be found), there would need to be at least 128 in the total sample.

Another limitation is that the research was done from transcripts of audiotapes. There were many utterances that were not understood by the researcher. If there had been video tapes to help in the translating of utterances, math references may have 
increased. Also, having video tapes would have given the researcher the context of play; for example, with whom, what, and where the child was playing.

An additional limitation is that the measurement for the experience of the provider only allowed the providers to indicate whether they had worked less than 1 year, 2 to 5 years, 5 to 10 years, 10 to 15 years, or more than 15 years. As Figure 3 indicated, there were fewer math references for children who were enrolled in programs where the caregiver had more experience. It would have beneficial to continue to determine exact years of experience beyond 15 years to see if the trend was that math utterances continued to increase up until a particular time. This would have helped to decipher whether there was possible burnout on the part of the provider and how they offered opportunities for math learning.

\section{Future Research}

Future research can easily build upon this study. Ginsburg and colleagues (2008) stated that prekindergarten math instruction is often in a very limited range. Providers often limit their teaching to basics such as counting to lower numbers such as 10 or 20 and naming everyday shapes (Graham, Nash, \& Paul, 1997). It would be useful to offer mathematical training for providers on the full spectrum of mathematics activities available and on how to offer specific math learning opportunities during free play. This could be done by explaining how children spontaneously discuss math, by showing how certain games support math talk, or by explaining ways in which to set up free play activities so as to enhance math talk. But, as Ginsburg and colleagues (2008) stated, 
offering play in order to support math is not enough. In addition, providers would need to be trained in how to identify when children spontaneously engaged in math talk and how to ask questions to encourage and enhance this math talk. As providers begin to feel more comfortable in providing math during free play, they may feel better prepared to enhance math skills through other instructional methods. This in turn would increase the opportunities for children to learn math in caregiving environments.

There is some practical significance in the results of the trends found when analyzing children's math utterances according to the experience and education of the provider. It would be beneficial to complete a similar study with a larger sample. A larger sample size would increase the likelihood of finding statistical significance, as previously mentioned in the limitations section. Building upon the current study would only increase practical significance.

As children are provided varying opportunities to increase their knowledge of mathematics through their daily activities, they will have the basics needed as they begin compulsory school. From there, they will be better qualified to learn more difficult math concepts at earlier ages, thus supporting higher math scores throughout the school years. 


\section{REFERENCES}

Baldi, S., Jin, Y., Skemer, M., Green, P. J., Herget, D., \& Xie, H., (2007). Highlights from PISA 2006: Performance of U.S. 15-year-old students in science and mathematics literacy in an international context (NCES 2008-016). National Center for Education Statistics, Institute of Education Sciences, U.S. Department of Education. Washington, DC. Retrieved from http://nces.ed.gov/pubsearch/ pubsinfo.asp?pubid=2008016

Berk, L. E., \& Winsler, A. (1995). Scaffolding children's learning: Vygotsky and early childhood education. Washington, DC: National Association for the Education of Young Children.

Blevins-Knabe, B., Austin, A. B., Musun, L., Eddy, A., \& Jones, R. M. (2000). Family home care providers' and parents' beliefs and practices concerning mathematics with young children. Early Childhood Development and Care, 165, 41-58. doi: $10.1080 / 0300443001650104$

Blevins-Knabe, B., Hendershot, S., Ota, C., \& Austin, A. B. (2011, April). Preschool children's math conversations in family home child care. In J. LeFevre (Chair), Children's early experiences with numeracy: Who's counting, where does it happen, and how much does it matter? Symposium conducted at Biennial Meeting of the Society of Research for Child Development, Montreal, CA.

Chien, N. C., Howes, C., Burchinal, M., Pianta, R. C., Ritchie, S., Bryant, D. M., ... Barbarin, O. A. (2010). Children's classroom engagement and school readiness 
gains in prekindergarten. Child Development, 81(5), 1534-1549. doi:

10.1111/j.1467-8624.2010.01490.x

Clements, D. H., \& Sarama, J. (2005). Math play. Early Childhood Today, 19(4), 50-57.

Retrieved from http://web.ebscohost.com.dist.lib.usu.edu/ehost/

detail?vid=11\&hid=7\&sid=a4cfe3b9-5e90-416c-bb52-dcc0cbbe $8 a 68 \%$

40sessionmgr11\&bdata=JnNpdGU9ZWhvc3QtbGl2ZQ\%3d\%3d\#db=aph\&AN=1 5635871

Copley, J. (2000). The young child and mathematics. Washington, DC: National Association for the Education of Young Children. Retrieved from http://www.naeyc.org/store/files/store/TOC/119.pdf

Ginsburg, H., Klein, A., \& Starkey, P. (1998). The development of children's mathematical thinking: Connecting research with practice. In I. Siegel \& K. Renninger (Eds.), Child psychology in practice (5th ed., pp. 401-476). New York, NY: Wiley.

Ginsburg, H. P., Lee, J. S., \& Boyd, J. S. (2008). Mathematics education for young children: What it is and how to promote it. Society for Research in Child Development, Social Policy Report, 22(1). Retrieved from http://www.srcd.org/ index.php?option=com_docman\&task=doc_dowload $\&$ gid $=85$

Ginsburg, H. P., Lin, C., Ness, D., \& Seo, K. H. (2003). Young American and Chinese children's everyday mathematical activity. Mathematical Thinking and Learning, 5(4), 235-258. Retrieved from http://web.ebscohost.com/ehost/detail? sid=e2cc384a-0a86-471d-8c61-e61493d18ee6\%40sessionmgr114\&vid=1\& 
hid=111\&bdata=JnNpdGU9ZWhvc3QtbG12ZQ\%3d\%3d\#db=mth\&AN=1080030 0

Graham, T. A., Nash, C., \& Paul, K. (1997). Young children's exposure to mathematics: The child care context. Early Childhood Education, 25(1), 31-38. Retrieved from http://web.ebscohost.com/ehost/pdfviewer/pdfviewer?sid=2af4388b-0e3f403c-ac61-3abec6eb6ea1\%40sessionmgr114\&vid=2\&hid=119

John-Steiner, V., \& Mahn, H. (1996). Sociocultural approaches to learning and development: A Vygotskian framework. Educational Psychologist, 31, 191-206. Retrieved from http://www.tlu.ee/ kpata/haridustehnoloogiaTLU/ sociocultural.pdf

Jordan, N. C., Kaplan, D., Locuniak, M. N., \& Ramineni, C. (2007). Predicting firstgrade math achievement from developmental number sense trajectories. Learning Disabilities Research \& Practice, 22(1), 36-46. Retrieved from http://www.udel.edu/ cmp2/jordan_LDRP2007.pdf

Klibanoff, R. S., Levine, S. C., Huttenlocher, J., Vasilyeva, M., \& Hedges, L. V. (2006). Preschool children's mathematical knowledge: The effect of teacher "math talk." Developmental Psychology, 42(1), 59-69. doi: 10.1037/0012-1649.42.1.59

Lee, J., Autry, M. M., Fox, J., \& Williams, C. (2008). Investigating children's mathematics readiness. Journal of Research in Childhood Education, 22(3), 316328. doi: 10.1080/02568540809594630

Lee, V. E., \& Burkam, D. T. (2002). Inequality at the starting gate: Social background differences in achievement as children begin school. Economic Policy Institute, 
Research for Broadly Shared Prosperity. Retrieved from http://www.epi.org/ publication/books_starting_gate/

LENA Foundation. (2011). Retrieved from http://www.lenafoundation.org/ProSystem/ Overview.aspx

Levine, S. C., Suriyakham, L. W., Rowe, M. L., Huttenlocher, J., \& Gunderson, E. A. (2010). What counts in the development of young children's number knowledge? Developmental Psychology, 46(5), 1309-1319. doi: 10.1037/a0019671

McLellan, S. (2010). Pedagogical documentation as research in early mathematics. The Alberta Journal of Educational Research, 56(1), 99-101. Retrieved from http://ajer.synergiesprairies.ca/ajer/index.php/ajer/article/viewFile/797/767

Mulligan, G. M., Brimhal, D., West, J., \& Chapman, C. (2005). Child care and early education arrangements of infants, toddlers, and preschoolers: 2001. (NCES 2006-039). U.S. Department of Education, National Center for Education Statistics, Washington, DC: U.S. Government Printing Office. Retrieved from http://nces.ed.gov/pubs2006/2006039.pdf

National Mathematics Advisory Panel (NMAP). (2008). Foundations for success: The final report of the national mathematics advisory panel. Washington, DC: U.S. Department of Education.

National Science Board. (2008). Science and engineering indicators 2008. Two volumes. Arlington, VA: National Science Foundation (Vol. 1, NSB 08-01; Vol. 2, NSB 08-01A). 
Ota, C. L. (2010). The relationships among caregiver training, mentoring, and turntaking between caregiver and child in family child care (Unpublished doctoral dissertation). Utah State University, Logan, UT.

Phillips, B. M., \& Morse, E. E. (2011). Family child care learning environments:

Caregiver knowledge and practices related to early literacy and mathematics. Early Childhood Education Journal, 39, 213-222. doi: 10.1007/s10643-0110456-y

QSR International. (2011). Retrieved from http://www.qsrinternational.com/ products_nvivo.aspx

Rogoff, B. (1990). Apprenticeship in thinking. New York, NY: Oxford University Press.

Sarama, J., \& Clements, D. H. (2005). How children "Think math." Early Childhood Today, 20(2), 11. Retrieved from http://web.ebscohost.com.dist.lib.usu.edu/ ehost/detail?vid=3\&hid=7\&sid=a4cfe3b9-5e90-416c-bb52-dcc0cbbe8a68\% 40sessionmgr11\&bdata=JnNpdGU9Z Whvc3QtbG12ZQ\%3d\%3d\# $\mathrm{db}=\mathrm{aph} \& \mathrm{AN}=18494787$

Shonkoff, J. P., \& Phillips, D. A. (2000). From neurons to neighborhoods: The science of early childhood development. Washington, DC: National Academy Press. Tudge, J. (2009). Methods of assessment of young children's informal mathematical experiences. Encyclopedia of language and literacy development, 1-7. London, ON: Canadian Language and Literacy Research Network. Retrieved from 
http://literacyencyclopedia.ca/pdfs/Methods_of_Assessment_of_Young_Children \%27s_Informal_Mathematical_Experiences.pdf

Tudge, J., \& Doucet, F. (2004). Early mathematical experiences: Observing young Black and White children's everyday activities. Early Childhood Research Quarterly, 19, 21-39. Retrieved from http://www.sciencedirect.com/science/article/ pii/S0885200604000080

Vygotsky, L. S. (1978). Mind in society: The development of higher psychological processes (M. Cole, V. John-Steiner, S. Scribern, \& E. Souberman, Eds.) Cambridge, MA: Harvard University Press.

Xu, D., Yapanel, U., \& Gray, S. (2009). Reliability of the LENA language environment analysis system in young children's natural home environment (LTR-05-2). Retrieved from http://www.lenafoundation.org/Research/TechnicalReports.aspx ?expand=LTR $-05-2$ 
APPENDICES 
Appendix A.

Coding System for Mathematical Content

Step 1 


\section{Coding System for Math Transcripts Step 1}

Coding System taken from Ginsburg, H., Lin, C., Ness, D., \& Seo, K. (2003). Young children and Chinese children's everyday mathematical activity. Mathematical Thinking and Learning, 5 (4) 235-258.

- Do not include teaching sessions or sessions in which teacher is only reading to children or giving directives. If the transcript was found to offer more teaching, directives to clean, or a teacher reading to the child, it was not coded for math references but was considered to be a 'teaching' transcript. If the transcript was considered as teaching, cleanup, or reading but there was more conversation (give and take) between teacher and child than directives and/or reading, it was coded for math references.

- If a word is repeated over and over when one child is talking, score it as one occurrence unless other words occur in between the repetitions. In this case, consider the other words a break and score it once per unit. For example, two, two, two shoe, two, two is coded two different times.

\section{Context codes (addition by Blevins-Knabe, 2000)}

- 1 With other child only

- 2 With teacher only

- 3 Alone

- 4 Other child and teacher

\section{Speaker: (addition by Blevins-Knabe, 2000)}

Child initiates - says something about number first

Peer initiates - says something about number first

Teacher initiates - says something about number first

How to decide how to score initiation:

- Each exchange (exchange could include a back and forth on same topic) gets scored as one initiation.

- Code each word/phrase for a speaker/initiation.

- If math content changes (if a new word is used) score as a new initiation. Even if new word is part of a string of words that have already been used, score as an initiation if that is the first time for that word in the immediate conversation. 
Appendix B.

Coding System for Mathematical Content

Step 2 


\section{Coding System for Mathematical Content Step 2}

- Each word or phrase gets one label

- Each main category has a number, but because 2, 3, \& 4 have subcategories 2, 3, $\& 4$ will never serve as a code, only the subcategory numbers will be used.

\begin{tabular}{|c|c|}
\hline Codes and Subcodes & Description \\
\hline 1-Classification & Systematic arrangement of groups according to clear criteria. \\
\hline 2-Magnitude & $\begin{array}{l}\text { Description of a magnitude ("There's a lot here") or comparison of } \\
\text { two or more items to evaluate relative magnitude. }\end{array}$ \\
\hline $\begin{array}{l}\text { 21-Saying quantity } \\
\text { or magnitude words }\end{array}$ & $\begin{array}{l}\text { This involves describing the global quantity or magnitude of objects, } \\
\text { as in "Oh, this is really big." The object may or may not be present } \\
\text { and the child may not compare two objects directly. Thus, the child } \\
\text { may say that she is "faster" than another without adducing direct } \\
\text { evidence to support the claim. (NVivo search for: little, big, lots, any, } \\
\text { many, long, tiny, lots, a lot, heavy, small, fast.) }\end{array}$ \\
\hline $\begin{array}{l}\text { 22-Empirical } \\
\text { matching }\end{array}$ & $\begin{array}{l}\text { Here the child makes a direct comparison of concrete objects, as when } \\
\text { one child looks at two structures standing side by side and proclaims, } \\
\text { "Mine is more bigger." }\end{array}$ \\
\hline $\begin{array}{l}\text { 23-Comparison } \\
\text { without quantification } \\
\text { (the er words) }\end{array}$ & $\begin{array}{l}\text { The child engages in magnitude in an approximate way, without exact } \\
\text { quantification. Thus, one child holds his arms apart to indicate that a } \\
\text { picture in a book is "this much scary" and another child disagrees, } \\
\text { holding his arms even wider apart and saying, "No, it this much } \\
\text { scary." (NVivo search for: more, much, some, longer, shorter, faster, } \\
\text { largest, larger, shortest, littlest, littler.) }\end{array}$ \\
\hline $\begin{array}{l}\text { 24-Comparison } \\
\text { with quantification }\end{array}$ & $\begin{array}{l}\text { The child compares dimensions using quantitative words. Thus, as two } \\
\text { children are building a structure one says "we need one more," } \\
\text { indicating that the line of blocks was too short by one. The child may } \\
\text { estimate the quantity or may measure it exactly. Example: (number } \\
\text { word) more, (number word) longer. }\end{array}$ \\
\hline $\begin{array}{l}\text { 25-Qualitative } \\
\text { comparison }\end{array}$ & $\begin{array}{l}\text { The child makes a comparison with an attempt at quantification, but } \\
\text { one that is inexact. Example: A little littler one, little shorter. } \\
\text { (Addition by Blevins-Knabe et al., 2000.) }\end{array}$ \\
\hline 3-Enumeration & Numerical judgment or quantification. \\
\hline $\begin{array}{l}\text { 31-Saying number } \\
\text { words }\end{array}$ & $\begin{array}{l}\text { The child simply says a number word. Example: I'm five years old. } \\
\text { (NVivo search for: one, two, three, four, five, six, seven, eight, nine, } \\
\text { ten, eleven, twelve, thirteen, fourteen, fifteen, sixteen, seventeen, } \\
\text { eighteen, nineteen, twenty, thirty, forty, hundred.) }\end{array}$ \\
\hline
\end{tabular}




\begin{tabular}{l} 
32-Counting \\
33-Subitizing/ \\
estimation \\
\\
34-Reading/writing \\
numbers \\
35-Dynamics \\
\hline
\end{tabular}

\section{Extra Nodes for Enumeration}

Number total- all

Number one-identifier

Number zero
Number position
Number time
Number question
Number Measure

\section{4-Pattern and Shape}

\begin{tabular}{|l|} 
41-Symmetry \\
42-Patterning \\
43-Figure \\
Identification \\
44-Shape Matching \\
\\
5-Spatial
\end{tabular}

The child overtly counts objects or says the number words without counting objects.

Without having counted, the child uses a number word to designate the cardinal value of a set. The child could have subitized the value - that is, perceived the number without counting - or the child could have estimated the cardinal values; there is no way for us to tell. In either case, the context makes it clear that the child is not simply producing a wild guess or randomly producing a number word.

The child reads numbers, for example on a calendar, or writes numbers, for example on a piece of paper.

Exploration of the process of change or transformation. For example, the child takes away the buttons on the table one by one and says, "Now I got two. Now I got one. Now I got none!"

\section{New codes for enumeration-definitions. (Addition by Blevins- Knabe et al., 2000.)}

Number total - when number used to refer to how many or all. Example: I have all of them. (NVivo search for: all, every, each.)

Number one identifier - often the word one is use to distinguish which object. It is not clear that this is a number meaning. Example: Give me that one.

Number zero- When number words are used to mean there is nothing. (NVivo search for: all gone, none, zero, no more, don't have any.)

Number position. Example: I was in line first. (NVivo search for: first, second, third, last, next.)

Example: All day, 8 o'clock. (NVivo search for: seconds, minutes, hours.)

(NVivo search for: count, how many, number.)

(NVivo search for: inches, feet.)

Exploration of patterns and spatial forms.

This involves an exploration of symmetrical relationship, involving a correspondence in size, shape, and relative position of parts on opposite sides of a dividing line, median plane, or axis.

Objects are arranged in a regular, rule-governed manner. Example: Heart, circle, heart, circle.

The child's behavior indicates recognition of particular shapes. (NVivo search for: square, circle, triangle, heart, dot, rectangle, cube.)

The child uses geometric properties of shape to complete a task or solve a problem.

Exploration of positions, directions, and distances in space. (NVivo search for around, by, in, on, out, over, under, up, down.) 


\begin{tabular}{|c|c|}
\hline Relations & \\
\hline 51-Around & E.g. So as to surround or envelop. \\
\hline $52-B y$ & E.g. Close to; next to. Example: The window by the door. \\
\hline $53-\operatorname{In}$ & $\begin{array}{l}\text { E.g. From the outside to a point within; into. Example: I threw the } \\
\text { letter in the wastebasket. }\end{array}$ \\
\hline $54-O n$ & E.g. In a position above, but in contact with and supported by; upon. \\
\hline $55-O u t$ & E.g. In a direction away from the inside. \\
\hline 56-Over & E.g. In, at, or to a position up from; higher than; above \\
\hline 57-Under & E.g. In, at, or to a position down from; lower than; below \\
\hline $58-U p$ & E.g. From a lower to a higher place; away from or out of the ground \\
\hline 6-Part/whole & $\begin{array}{l}\text { Says part or whole. (Addition by Blevins-Knabe et al., 2000.) } \\
\text { (NVivo search for: part, whole, half.) }\end{array}$ \\
\hline
\end{tabular}


Appendix C.

Code Book for Step 2 


\section{Coding System for Mathematical Content}

\section{Booklet}

1- Classification: Systematic arrangement of groups according to clear criteria. For example, the child sorts blocks into groups of cubes and cylinders.

2- Magnitude: Description of a magnitude ("There's a lot here") or comparison of two or more items to evaluate relative magnitude. For example, the child claims that his tower is "more higher" than his friend's.

Sub-code for Magnitude

21-Saying quantity or magnitude words. This involves describing the global quantity or magnitude of objects, as in "Oh, this is really big." The object may or may not be present and the child may not compare two objects directly. Thus, the child may say that she is "faster" than another without adducing direct evidence to support the claim. Other words that fit here: all, none, some, everybody.

Some

- being an unspecified number or quantity: some people came into the room

- an indefinite or unspecified number or portion: we took some of the books to the auction

High

- greater in size, amount, degree, power, intensity, etc. than usual: high prices, high voltage, a high profile

22-Empirical matching. Here the child makes a direct comparison of concrete objects, as when one child looks at two structures standing side by side and proclaims, "Mine is more bigger."

23-Comparison without quantification. The child engages in magnitude in an approximate way, without exact quantification. Thus, one child holds his arms apart to indicate that a picture in a book is "this much scary" and another child disagrees, holding his arms even wider apart and saying, "No, it this much scary."

24-Comparison with quantification. The child compares dimensions using quantitative words. Thus, as two children are building a structure, one says, "We need one more," indicating essentially that the line of blocks was too short by one. The child may estimate the quantity or may measure it exactly.

25-Qualitative comparison. The child makes a comparison with an attempt at quantification, but one that is inexact. Example: "A little littler one" or "little shorter." (Addition by Blevins-Knabe et al., 2000.) 
3- Enumeration: Numerical judgment or quantification. For example, the child says that she has "three" blocks.

Sub codes for enumeration involved the following categories:

31-Saying number words. The child simply says a number word, as in "I'm five years old" or "I got it first." Half, both, another (when meaning is one more). Not when meaning is 'none'.

One (www.yourdictionary.com) code as 31 unless the use does not fit these definitions:

- being a single thing or unit; not two or more

- characterized by unity; forming a whole; united; undivided: with one accord

- $\quad$ single in kind; the same: all of one mind

- the number expressing unity or designating a single unit: the lowest cardinal number and the first used in counting a series; 1 ; I

- a single person or thing

- something numbered one or marked with one pip, as the face of a die or domino

32-Counting. The child overtly counts objects or says the number words without counting objects.

33-Subitizing/estimation. Without having counted, the child uses a number word to designate the cardinal value of a set. The child could have subitized the value - that is, perceived the number without counting - or the child could have estimated the cardinal values; there is no way for us to tell. In either case, the context makes it clear that the child is not simply producing a wild guess or randomly producing a number word.

34-Reading/writing numbers. The child reads numbers, for example on a calendar, or writes numbers, for example on a piece of paper.

35-Dynamics: Exploration of the process of change or transformation. For example, the child takes away the buttons on the table one by one and says, "Now I got two. Now I got one. Now I got none!"

4- Pattern and Shape: Exploration of patterns and spatial forms. For example, the child makes a symmetrical tower or identifies an object as "square."

Sub-codes for pattern and shape involved the following categories:

41-Symmetry. This involves an exploration of symmetrical relationship, involving a correspondence in size, shape, and relative position of parts on opposite sides of a dividing line, median plane, or axis. For example, a child draws a picture of a butterfly in which the body serves as a line of symmetry and one of the wings is a mirror image of the other. Or a child uses Lego's to construct a building in which the towers and 
windows on the left and right sides are identical to one another in terms of number, size and shape.

42-Patterning. Objects are arranged in a regular, rule-governed manner. For example, a child places several rectangular magnets in a row, evenly spaced, and then places another triangular magnet on each. Example: white, yellow, black, white, yellow, black.

43-Figure Identification. The child's behavior indicates recognition of particular shapes. For example, during clean-up time, the child places all the cubes in one bin, the rectangular prisms in another, and so on. Or the child consistently calls the cubes "squares" and does not apply this label to cylinders (which might be called "circle things"). The criterion is the child's consistent ability to identify a shape, not necessarily to label it correctly.

44-Shape Matching. The child uses geometric properties of shape to complete a task or solve a problem. For example, to complete part of a puzzle, a child uses a particular piece because it has a straight edge on one side and a certain contour on another.

5- Spatial Relations: Exploration of positions, directions, and distances in space. For example, the child notes that one block is "under" another.

Defined as the use of the prepositions: around, beside, between by, down, in, inside, near, on, out, outside, over, under, underneath, up; any direction words such as north, south, east, west, around.

Some spatial definitions for prepositions with multiple meanings: (all definitions from www.yourdictionary.com).

$\underline{\text { Around }}$

round; esp.,

1. in a circle; along a circular course or circumference

2. in or through a course or circuit, as from one place to another

3. on all sides; in every direction

4. in circumference

5. in or to the opposite direction, belief, etc

- $\quad$ so as to surround or envelop

By

- close to; next to: the window by the door

$\underline{\text { In }}$

- from the outside to a point within; into: threw the letter in the wastebasket 
$\underline{\text { On }}$

- in a position above, but in contact with and supported by; upon

Out

- in a direction away from the inside: let's go out and look at the stars

- away from the center or middle: the troops fanned out

- from inside a building or shelter into the open air; outside: the boy went out to play

- from within a container or source: drained the water out

$\underline{\text { Over }}$

- in, at, or to a position up from; higher than; above: a canopy over the bed, in water over his knees

- on top of: a blanket over the bed

$\underline{\text { Under }}$

- in, at, or to a position down from; lower than; below: shoes under the bed, under a blazing sun beneath the surface of: under water

- below and to the other side of: we drove under a bridge

- covered, surmounted, enveloped, or concealed by: to wear a vest under a coat

$\underline{\mathrm{Up}}$

- from a lower to a higher place; away from or out of the ground

- in or on a higher position or level; off the ground, or from a position below to one at the surface of the earth or water

- in a direction or place thought of as higher or above

- above the horizon

6-Part-whole: -I want part. (Addition by Blevins-Knabe et al., 2000.) 


\section{NVivo Text Queries:}

\section{Magnitude}

1. long, longer, longest, short, shorter, shortest, fast, faster, fastest, more, much, big, bigger biggest, little, littler, littlest, large, larger, largest, tiny, some, any, lots, a lot

Add really after finished

\section{Enumeration}

2. one, two, three, four, five, six, seven, eight, nine, ten, eleven, twelve, thirteen, fourteen, fifteen, sixteen, seventeen, eighteen, nineteen, twenty, none, zero, all, all gone, first, second, third, fourth

Pattern and Shape

3. square, rectangle, circle, line, cube

Spatial

4. around, by in, on, out, over, under, up, down

Part/whole

5. half, whole, part

extra words

6. Small, each, every, last, don't have any, many, heavy, heavier, heaviest, light, lighter, lightest

extra words II

7. Words to add

Count, how many, number, inches, feet, seconds, minutes, hours

\section{Coding Tips}

For each coded interaction:

1. Code who says it

Node speaker child is Target child

Node speaker other child is Other child ( I think this got translated into child)

Node speaker Teacher is teacher

2. Code-conversational partner (who is present)

Code as 'teacher' if target child is speaking only to the teacher.

Code as 'peer' if target child is speaking only to another child.

Code as 'all' if target child is speaking to the teacher and another child(ren).

Code as 'alone' if target child is speaking to themself.

\section{General notes:}

When coding look at surrounding words and code enough of them to help in interpreting meaning. 
If surrounding words are in same broad category for example, some more, code it at one node as one phrase. For example, for words like 'some', code words it goes with (i.e. some yellow, some blue blocks. 'All gone' is one phrase.

Same word repeated with about the same meaning-score only once; put both in same node. If the second occurrence seems to add a new meaning, score it by itself.

On numbers when one speaker uses several numbers in one turn code as one phrase or reference. For example, 'one, two, three, four, ...one, two, three, four, five, six', code it all as one phrase.

If there is a typo or ambiguous translation (for example, 'two' instead of 'too' or 'one' instead of 'on') don't code. Or if the word is used ambiguously, don't code.

\section{Meanings that are not coded:}

1. Clean up or wake up, watch out, back up, out there, out of here, look down in the (word), time's up, throw up, wait up, come on, in the way, in trouble, telling on, on the computer, rubbed it in, in the circus, on the way, leave it on, last time, next time.

2. Any use that seems off color or ambiguous. 
Appendix D.

Sample Transcript 


\section{Sample Transcript}

\section{5-3_2_2}

TC: No you're not. No, no we're not. Are, are we...?

T: No pinching. No pinching.

TC: I do it for a while. (word), to the rescue (sung).

OC: Mom, mom, mom, mom.

TC: What?

OC: Hey, mom.

TC: What? I'm not daddy, I'm mommy.

OC: Mom.

TC: Daddy.

OC: What?

TC: Daddy. Daddy, daddy, daddy, daddy.

OC: What?

TC: Daddy, daddy. Daddy. Daddy. Daddy. Daddy.

OC: Daddy or mom? Dadda. Dadda. Daddy, daddy, daddy, daddy (continues on numerous times).

TC: $\quad$ La, la, la, la. Hi, la-la. (word) to the rescue. (Makes singing noises.) Can I have one? Can I have one? I have to go potty. Ellen, I go to potty. I need to go potty. ...go potty. (Makes noises. Laughs.)

T: $\quad$ Savannah, you haven't even started eating yet. Drink all your milk now.

TC: Okay. (Makes noises.) I saw one at Uncle (word) house. I (word) on those.

Hey, Ellen, I have two (word).

T: Yeah?

OC: (words)

TC: No you don't. Only I do. I do have boy sandals on. Can I have one?

T: $\quad$ You guys get your shoes on and then you can go outside and run around. Well, you know what? It's probably too cold now. You can go downstairs and play for a bit. Okay?

TC: Yeah. No, no. Okay.

TC: target child; OC: other child (does not depict a particular child); T: teacher (Words in parentheses shows abstract noises or words not understood.) 
Appendix E.

Sample Coded Transcript 


\section{Sample Coded Transcript}

Sample of a coded transcript in NVivo. The stripes on the side show where words were coded. When the stripe is clicked, it highlights the words that were coded for that code.

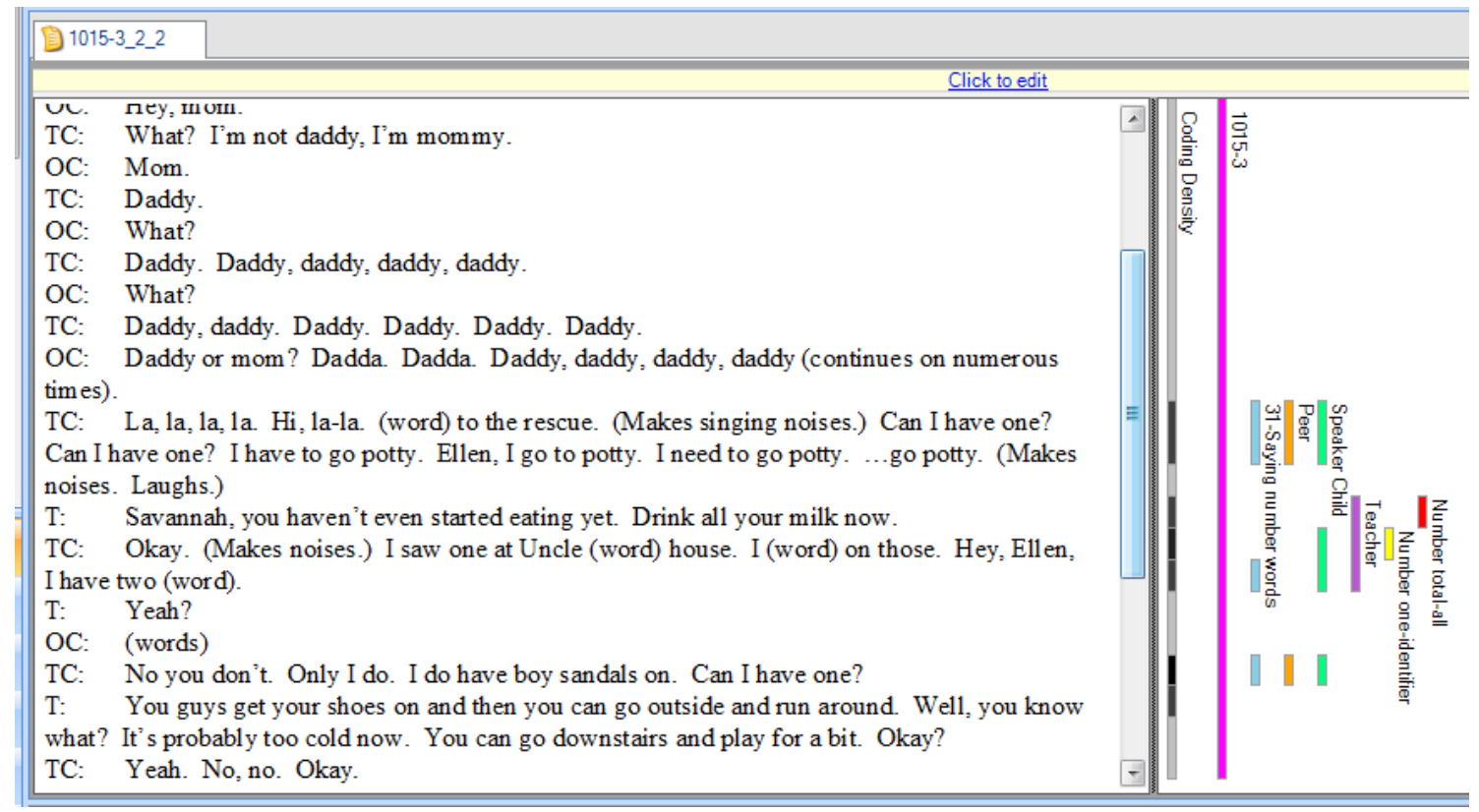

Highlighted words are those coded for "31-Saying number words."

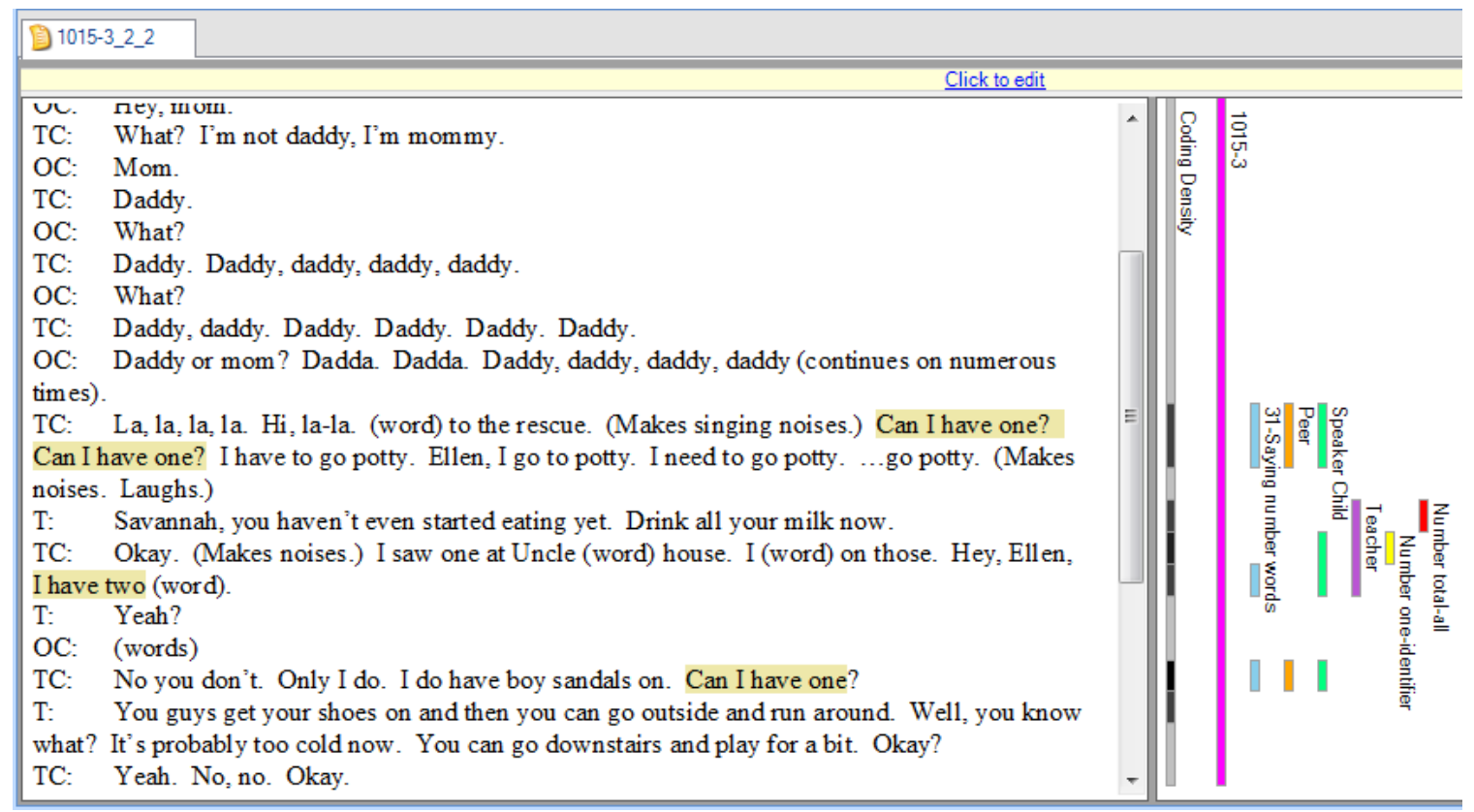

